\title{
Solar Sail Topology Variations Due to On-Orbit Thermal Effects
}

\author{
Jeremy A. Banik ${ }^{*}$ \\ South Dakota School of Mines and Technology, Rapid City, South Dakota 57701 \\ Peter S. Lively \\ Lockheed Martin Space Operations, NASA Langley Research Center, Hampton, Virginia 23681 \\ Barmac K. Taleghani. ${ }^{\ddagger}$ \\ Army Research Laboratory, NASA Langley Research Center, Hampton, Virginia 23681 \\ and \\ Christopher H. Jenkins ${ }^{\S}$ \\ Montana State University, Bozeman, Montana 59717
}

\begin{abstract}
The objective of this research was to predict the influence of non-uniform temperature distribution on solar sail topology and the effect of such topology variations on sail performance (thrust, torque). Specifically considered were the thermal effects due to onorbit attitude control maneuvers. Such maneuvers are expected to advance the sail to a position off-normal to the sun by as much as 35 degrees; a solar sail initially deformed by typical pre-tension and solar pressure loads may suffer significant thermally induced strains due to the non-uniform heating caused by these maneuvers. This on-orbit scenario was investigated through development of an automated analytical shape model that iterates many times between sail shape and sail temperature distribution before converging on a final coupled thermal structural affected sail topology. This model utilizes a validated geometrically non-linear finite element model and a thermal radiation subroutine. It was discovered that temperature gradients were deterministic for the off-normal solar angle cases as were thermally induced strains. Performance effects were found to be moderately significant but not as large as initially suspected. A roll torque was detected, and the sail center of pressure shifted by a distance that may influence on-orbit sail control stability.
\end{abstract}

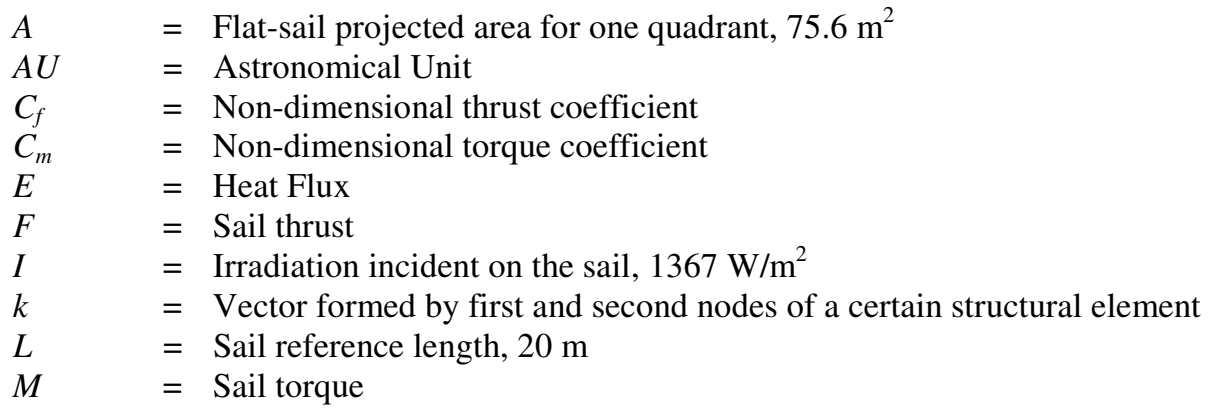

\footnotetext{
* Research Assistant, Compliant Structures Laboratory, 501 East Saint Joseph St., AIAA Student Member.

Sr. Aeronautical Engineer, Structural Dynamics Branch, 4B W Taylor St., AIAA Member.

* Sr. Mechanical Engineer, Structural Dynamics Branch, 4B W Taylor St., AIAA Member.

$\S$ Professor and Head, Mechanical and Industrial Engineering Department, 220 Roberts Hall, P.O. Box 173800, AIAA Associate Fellow.
} 


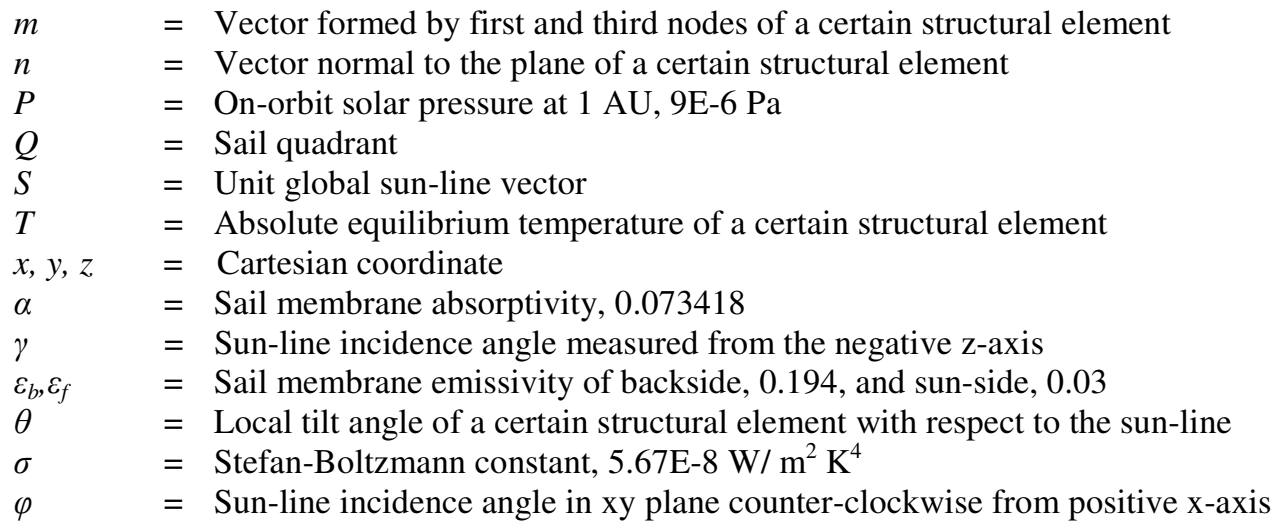

\section{Introduction}

OLAR sailing is a unique form of in-space propulsion that does not rely on traditional reaction mass thrust $\checkmark$ methods. Constant acceleration is produced through the momentum exchange from the reflection of photons over the large, deployed structure. As gossamer space structures that can be packaged into a tight volume, solar sail technology offers exclusive capabilities for many near term NASA missions such as the Geostorm Warning and the Solar Polar Imager. Ensuring the success of future solar sail missions requires validation of necessary technologies in a vacuum environment. Full ground validations are not possible for full-scale solar sails larger than approximately 20 meters. Therefore, characterizing sail behavior analytically is critical to mission success.

Of particular importance is realistically modeling sail surface topology. Such predictions are vital to developing robust thrust control techniques because any deviation from an expected on-orbit sail shape could render a sail unstable and uncontrollable. It has been stated by those developing thrust control techniques that asymmetries in sail topology are of particular concern because asymmetries induce a roll torque or a shift in center of pressure $(\mathrm{CP}){ }^{1}$ Non-uniform heating may be the primary basis of topology asymmetry because thermally-induced strains due to small temperature gradients are on the same order of magnitude as strains caused by typical mechanical pre-tension loads in the sail. Two distinct scenarios are suspected to be the primary source of non-uniform solar sail heating: variations in membrane surface optical properties or an off-normal orientation of the sailcraft with the respect to the sun-line. ${ }^{1}$ The second scenario will be the main focus of this investigation.

\section{A. Background}

Gossamer structures as a whole present new possibilities in the space community through low-mass, low-cost alternatives to mechanically deployed space structures. Many inflatable deployed space structures have been demonstrated since the 1950s. Significant milestone demonstrations include the Echo Balloon series in the 1950s and 1960s, the Goodyear antennas from the 1960s, sunshades in the 1970s and 1980s, the L'Garde inflatable decoys from the 1970s and 1980s, and the L'Garde inflatable antenna experiment launched from the space shuttle in $1996 .{ }^{2}$ To date, however, no controlled solar sail has been successfully demonstrated in-space.

The fundamental concept of solar sailing has been around for many years. As early as the 1920s, writings began to emerge about "using the pressure of sunlight to attain cosmic velocities" by the Soviets Tsiolkovsky and Tsander. ${ }^{3}$ The idea then lay dormant for many years before NASA and others began recognizing the potential of the technology and investing in its development. Now in recent years, significant advances in solar sail technologies have taken place. Such advances in design, manufacture, and analysis have brought the technology to a point where a validation flight mission is a near-term possibility.

Advances in solar sail technology are largely the product of recent ground demonstrations funded by the NASA In-Space Propulsion Office. Two full 20-meter solar sail systems were subjected to deployment, static, and dynamic tests in a relevant space-like environment. This effort was intended to demonstrate solar sails at a Technology Readiness Level 6. The two solar sail systems have been developed by L'Garde, Inc. and Alliant Techsystems Space Systems Division (ATK). Both systems are shown in Fig. 1 as they rest in the Space Power Facility chamber at NASA Glenn Research Center (GRC) during ground validation tests over the summer of 2005. 


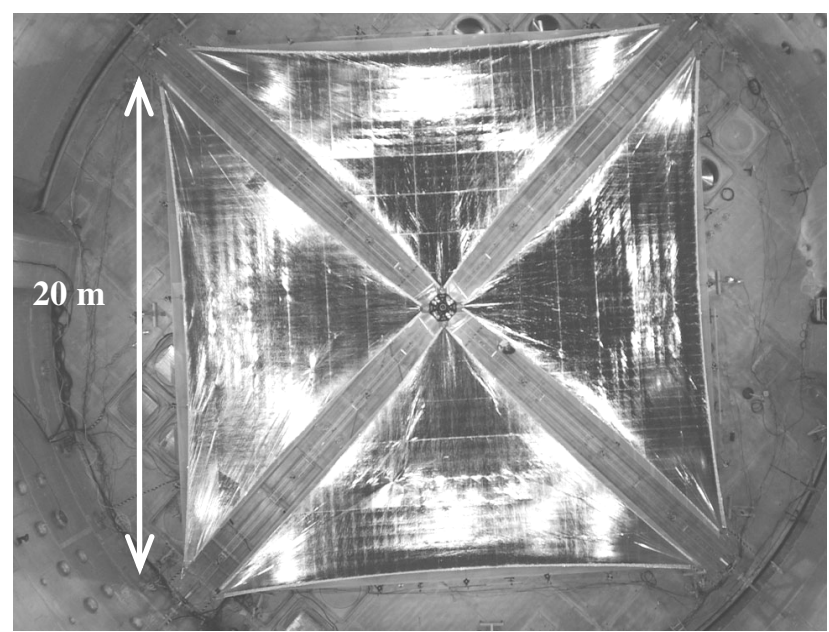

a) ATK Scalable Square Solar Sail $\left(\mathbf{S}^{\mathbf{4}}\right)$

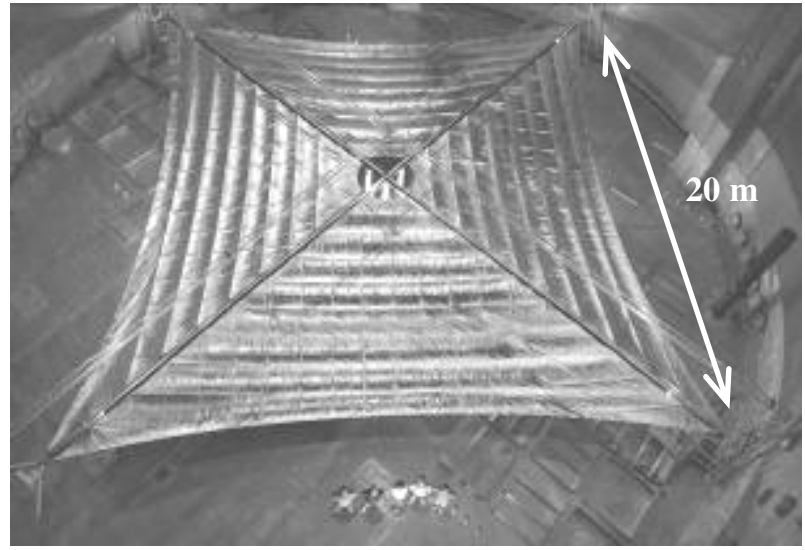

b) L'Garde sailcraft

Figure 1. Two 20-meter solar sail systems were concurrently developed and demonstrated.

\section{B. Literature Review}

Recently, significant work has been done in the area of structural analysis of solar sails, specifically using finite element modeling. Much of the recent progress in solar sail structural analysis can be attributed to the test-analysis correlation efforts during recent deployment demonstrations.

L'Garde, the NASA Langley Research Center (LaRC), ATK, SRS Technologies, and others have all invested considerable time in developing finite element models (FEM) of solar sails, albeit from many different approaches. L'Garde has used the NASTRAN finite element code with shell elements and tension-only cable elements for the sail membrane and sail cords, respectively. ${ }^{4}$ LaRC has used both the NASTRAN and ABAQUS codes with both shell and membrane elements for the sail area and beam elements for the sail cords. ATK and SRS have used the ANSYS and ALGOR finite element codes respectively. Also, different element geometries have been used to model this highly geometrically non-linear membrane structure; such geometries include both quadrilateral and triangular. ${ }^{4}$

Developing high fidelity models of complex solar sail structures is a challenging task of significant importance. Modeling the shear compliant border component of the ATK sail is particularly challenging and has recently been gaining more attention as different approaches are being investigated such as the use of either 2D quadrilateral or 1D tension-only elements. ${ }^{5}$ This border was designed to alleviate any strain mismatch between the sail membrane and the perimeter cord. Models are also being developed to predict the general location, size, and directionality of membrane wrinkles across the sail area.,

Both measuring and modeling thermal effects on solar sails has recently been gaining attention as well. For example, thermal testing was conducted at GRC where the temperature of a flat sail quadrant was measured for varying solar angles. ${ }^{7}$ Conversely, McInnes ${ }^{8}$ and others have done work to define the theoretical relationships necessary to calculate temperature of a flat sail for a given solar flux, solar angle, solar distance, and sail membrane optical properties.

To date most of these thermal test and modeling efforts have focused only on the effects of a uniform temperature distribution on a flat sail membrane. In reality, one would not expect this to be the case. Miles ${ }^{9}$ has begun to experimentally characterize non-uniform temperature distribution on a membrane specimen. In fact, Perrygo ${ }^{10}$ has predicted that if a membrane is heated non-uniformly the hotter regions will sag lower and the cooler regions will sag less due to a non-zero membrane coefficient of thermal expansion (CTE). Banik ${ }^{11}$ has thoroughly investigated structural-thermal response in curved sail.

\section{Objectives}

Therefore, the objective of this research is to predict the influence of non-uniform temperature distribution on solar sail topology and the effect of such topology variations on sail performance including thrust, torque, and CP predictions. Specific thermal cases considered were those due to on-orbit attitude control maneuvers that will typically advance the sail to a position off-normal to the sun by as much as 35 degrees, the angle corresponding to maximum tangential thrust. It is proposed that this off-normal solar incidence will induce thermal strains in the sail sufficient to affect sail symmetry, and that such asymmetries will significantly affect sail performance. 
Thermal/structural analysis techniques developed through this research are intended to aid future solar sail and other gossamer spacecraft development efforts.

\section{Shape model}

Research objectives were achieved in part through development of an analytical shape model that iterates many times between sail shape and sail temperature distribution before converging on a final thermal-structural sail topology. This automated shape model utilizes a geometrically non-linear MSC NASTRAN ${ }^{12,13}$ finite element model and a MATLAB coded thermal radiation subroutine. Once final sail topology has been determined, changes in sail performance are predicted using the IODA-Sail software package developed by SRS Technologies.

\section{A. Theory}

Several sources of thermal energy may be considered while investigating on-orbit solar sail heating depending on sailcraft design and mission application. Such sources include on-board power systems, solar energy directly from the sun, directly from a nearby planet, or reflected from a nearby planet. ${ }^{9}$ For this study, the shape model will be developed to characterize solar heating during a flight validation mission at $1 \mathrm{AU}$.

Radiation is the dominant heat transfer mode for gossamer structures in space. ${ }^{9}$ Conduction heating between sail elements is negligible because the thermal conductivity of a typical membrane material is small, and the conduction path is infinite. Heating due to convection is predictably minor for a near-zero air density in deep space. Transient heating effects are also not considered because in the case of a solar sail attitude adjustment maneuvers occur very slowly, especially when compared to the rate at which steady-state temperature is achieved in a low density, thin ( $5 \mu \mathrm{m}$ or less), sail membrane material. Radiation transferred between elements is negligible because the projected area between elements is nearly zero for the small sail billow depth of $5 \mathrm{~mm}$ analyzed in this study. Sail heating effects due to the $3 \mathrm{~K}$ space background temperature is neglected as well.

Several assumptions are listed regarding the optical condition of the membrane surface: (1) opaque, (2) specular reflectivity, (3) diffuse, gray emissivity. The first assumption neglects any energy transmitted through the membrane, indicating that the absorptivity is related to the inverse reflectivity. The second assumption signifies that the sun-line angle of incidence is equal to the angle of reflection. Third, a gray and diffuse emissivity assumes that radiation energy is emitted independent of wavelength and direction respectively.

True emissivity, however, is not independent of wavelength and direction, nor is temperature for that matter. However, it should be noted that the dependence of emissivity on temperature is minor compared to its dependence on wavelength or direction for the relatively cool sail operating temperature of $25{ }^{\circ} \mathrm{C}$. Electromagnetic wavelength can have a varied impact on the temperature of an object depending on the wavelength range considered. It turns out that the infrared wavelength range $(0.8$ to $100 \mu \mathrm{m})$ has the greatest effect on the temperature of an object. ${ }^{9}$ Therefore emissivity and absorptivity properties used in this thermal study were averaged within the infrared wavelength band. For example, hemispherical emissivity was measured and averaged over the 2 to $25 \mu \mathrm{m}$ wavelength band (infared) by SRS Technologies for both the sun-side and backside surfaces of the aluminized CP1.

A thermal radiation subroutine was developed after consideration of the previously discussed assumptions. This MATLAB subroutine utilizes the structural elements created by NASTRAN to assemble a separate thermalradiation model from a similar finite element approach. Temperature of each sail structural element was calculated individually through a radiation energy balance similar to that used by McInnes ${ }^{8}$. This balance considers several sources of radiation heating including the irradiation absorbed into the sail, expressed as

$$
E_{\text {absorbed }}=\alpha I \cos \theta(\text { Ref. 14) }
$$

and the energy emitted from both the front and back surfaces of the sail is given by

$$
\mathrm{E}_{\text {emitted }}=\sigma\left(\varepsilon_{\mathrm{f}}+\varepsilon_{\mathrm{b}}\right) \mathrm{T}^{4} \text { (Ref. 14) }
$$

The net rate of radiation heat transfer to the surface of an individual element is then determined from the following energy balance with substitutions from Eqns. 1 and 2:

$$
\begin{gathered}
\mathrm{E}_{\text {net, }, \text { rad }}=\mathrm{E}_{\text {absorbed }}-\mathrm{E}_{\text {emitted }} \\
\mathrm{E}_{\text {net, }, \text { rad }}=\alpha \mathrm{I} \cos \theta-\sigma\left(\varepsilon_{\mathrm{f}}+\varepsilon_{\mathrm{b}}\right) \mathrm{T}^{4}
\end{gathered}
$$


For a steady-state thermal-radiation model, the left-side term is zero, allowing Eqn. 3 to be rearranged giving the final equilibrium temperature of each element as

$$
\mathrm{T}=\left[\mathrm{AU} \frac{\alpha}{\varepsilon_{\mathrm{f}}+\varepsilon_{\mathrm{b}}}\left(\frac{\mathrm{I}}{\sigma}\right) \cos \theta\right]^{\frac{1}{4}}
$$

The AU constant was added for the sake of generality even though it has no effect on sail temperature for this study. As previously discussed, the AU constant (one sun-Earth distance) is assumed to be 1 for a flight validation mission. It should be noted that Eqn. 4 is of the same form as that used by McInnes ${ }^{8}$ to describe the uniform solar sail equilibrium temperature. The difference between them is in the definition of $\theta$. Eqn. 4 defines the angle $\theta$ to be the incidence of a certain, flat, sail element with respect to the sun-line while McInnes uses this angle to designate the incidence of an entirely flat sail with respect to the sun-line.

\section{B. Shape Model Architecture}

Predicting thermal effects on solar sail shape requires accounting for both structural and thermal load conditions, solar pressure and solar heating. In reality this thermal-structural interaction in the sail is a coupled effect. For example, the solar pressure and sail temperature both affect sail shape and are both simultaneously acting on the sail. Therefore, an automated shape model was developed to iterate between the FEM predicted sail shape and MATLAB predicted sail temperature distribution. Fig. 2. illustrates the iterative procedure used in this shape model.

Before executing a shape model analysis cycle, an FEM input file is created to represent a solar sail with typical on-orbit solar pressure and pre-tension loads. Once this file has been created, the shape model user defines specific solar parameters to be used in the thermal radiation subroutine. Once started, the shape model first executes the FEM input file to predict the initial sail topology without thermal effects considered. Once this initial sail shape has been calculated, the shape model passes a text file of FEM node coordinates to the MATLAB thermal radiation subroutine. The subroutine then predicts temperature of each FEM structural element according to the orientation of each element with respect to the user-defined sun-line position. A text file of element temperatures is then passed back to the FEM to predict the new sail topology due to both thermal and structural loads. After this new sail shape has been predicted, the shape model checks the root-mean-squared (RMS) difference between the new and old nodal positions. If the RMS difference is greater than $1 \%$ of the initial maximum sail deflection, the shape model continues iterating between sail temperature and sail topology. Once the shape model has finally converged, a "simple model geometry" file is manually uploaded into the IODA-Sail software. This software then calculates sail performance values according to the final thermal-structural sail topology.

Notice that the shape model convergence criterion was selected based upon the initial sail deflection rather than a criterion that compares the difference between successive sail topologies. The former convergence criterion was used because of the small regions of highly displaced node deflections due to local element buckling. The number of buckled elements in the model is few, yet these elements disrupt the RMS calculation used in convergence calculations. For example, the final position of a buckled element may be drastically different between successive finite element analyses. This causes large variations in the position of nodes associated with these buckled elements. Therefore a convergence criterion was selected based upon preliminary manual iterations between sail shape and sail temperature. Through these manual iterations, it was determined that an RMS difference equal to $1 \%$ of the initial maximum sail deflection was sufficient to capture thermally-induced topology variations for the loads applied in this investigation. A more comprehensive discussion of element buckling is to follow. 


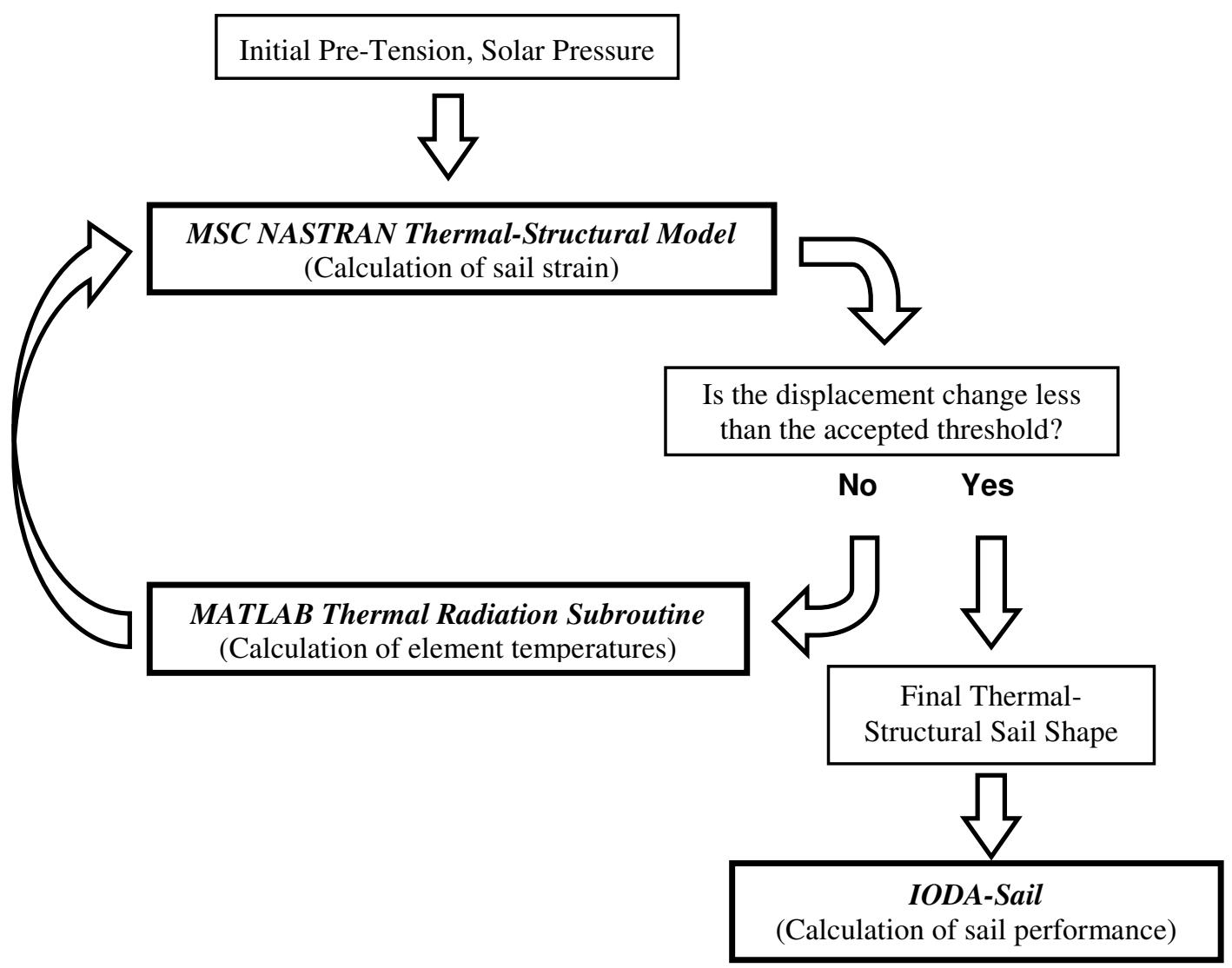

Figure 2. Architecture of the shape model

\section{Finite Element Thermal-Structural Model}

Dimensions of the FEM used in the shape model characterize one quadrant of the 20-meter ATK S4 system. Sail support booms are removed for computational efficiency as their contribution to on-orbit mechanical sail deformation is predicted negligible due to their much greater stiffness compared to that of the membrane. While thermally-induced boom deformations may affect on-orbit sail topology, these effects are neglected in this study because the CTE of the boom material is negligibly small compared to the CTE of the membrane material.

The MSC PATRAN pre/post processor was used to create geometry of the FEM for analysis by the non-linear MSC NASTRAN solver. Solar sails are known to be highly geometrically non-linear structures due to the large outof-plane displacements compared to the membrane thickness ( $5 \mu \mathrm{m}$ or less). Such large displacements arise when ultra-thin, highly compliant membranes are subjected to out-of-plane loading while under small initial stress $(7 \mathrm{kPa})$. Furthermore, the transition from in-plane to out-of-plane deformation in solar sails is numerically highly unstable because the membrane material has zero bending stiffness, resulting in a temporary rigid-body motion. Many of the convergence difficulties encountered in model development during this study were traced back to this issue of nonlinearity. In fact, it was sometimes necessary to employ certain procedures during model development to coax convergence. For example, the solar pressure load was applied in small increments initially during the transition from in-plane to out-of-plane deformation, and the halyard cord attach points were initially rotated slightly to allow for a more uniform stress distribution and then replaced to the original configuration in the final step. Linear constitutive relations suffice to represent the material behavior of solar sails, at least for an non-creased, pristine membrane material.

Loads and boundary conditions applied to the model represent a sail on-orbit at $1 \mathrm{AU}$ as listed in the following: $1 \mathrm{~N}$ pre-tension ( $7 \mathrm{kPa}$ stress at sail center) applied to the two halyard lines using a thermal load, 9E-6 Pa solar pressure, and a pinned boundary condition at the tack and halyard line attach points as indicated in Fig. 3. Total number of nodes and elements in the FEM is 5595 and 11688 respectively. 
Triangular, three-node, linear interpolation TRIA3 elements of $12.5 \mathrm{~cm}$ average edge length were used to represent the $3.58 \mu \mathrm{m}$ thick (including coating) aluminized CP1 membrane material. This element size was chosen through a mesh convergence study ${ }^{15}$ performed in a separate investigation.

The rip stop component of the sail was modeled using first-order, two-node, CROD elements oriented in series. This component can be identified in Fig. 3 as the "checker board" pattern. Each 1D rip stop element is the same length as each membrane element edge to which it attaches. A non-structural mass was included in the rip stop elements to account for weight of rip stop lines in a 1-g validation environment.

The halyard lines, tack line, and perimeter cord components were all modeled as two-node, first-order, 1D CBEAM elements. Location of these components is shown in Fig. 3. The tack line and halyard lines are located at the $90^{\circ}$ and $45^{\circ}$ corners respectively. The perimeter cord runs along the three scalloped sail edges. This cord carries most of the pre-tension load that is applied at the two halyard lines. This $1 \mathrm{~N}$ pretension is modeled using a thermal load to ensure the tension remains constant throughout high sail deformations.

Three jumper straps are included in the FEM located at each of the three sail corners. These straps attach the tack and halyard lines directly to the membrane at each respective corner. One of the halyard corner jumper straps is identified in Fig. 3. According to the sail designers, the purpose of the jumper straps is to alleviate high membrane stress levels that tend to form near the sail corners in a 1-g environment. The straps are designed to be in a slack condition until some critical sail deformation is reached (induced in a 1-g environment only). Jumper straps were modeled as two-node, first-order CROD elements with a thermal load applied to simulate the previously discussed slack condition and a non-linear stress-strain curve to allow for near-zero compressive stiffness.

The shear compliant border is a critical sail component that has a significant influence on sail deformation patterns. Others in the field have taken several approaches to modeling the border. It has been demonstrated by Leifler ${ }^{5}$ that 2D quadrilateral and $1 \mathrm{D}$ tension-only elements both provide a good approximation of the structural performance of the border. SRS Technologies intends the shear compliant border to compensate for induced structural and thermal strain mismatch between the sail membrane and the perimeter cord. ${ }^{4}$ For ease of convergence, two-node, first-order, 1D CROD elements were used in this study to represent the shear compliant border rather than the troublesome 2D quadrilateral elements.

A series of these CROD elements were oriented perpendicular to the sail membrane at each of the outer membrane nodes. The outer edges of the border elements were attached to the perimeter cord. Cross-section area of each CROD element was chosen to geometrically represent the cross-section area of the specific 2D shear compliant border section represented by each 1D element. Because the shear compliant border is not physically capable of sustaining a compressive load, a non-linear material property was used in the CROD border elements to allow for very low compressive stiffness under a negative strain condition.

Several other, less critical, sail components were accounted for in the FEM. Such components include corner reinforcements, cone attach straps, and rip stop seams. None of these components required any additional elements. Instead the geometries of previously discussed elements were adjusted slightly at specific locations. For example, membrane thickness and shear border element cross-section area were both increased slightly near the sail corners to represent the corner reinforcement and cone attach straps respectively. The rip stop seams were represented by slightly increasing the cross-section area of the rip stop elements that run parallel to the sail hypotenuse.

Fig. 3 shows the sail centerline designated from the tack line to the sail hypotenuse. Later, 2D sail billow profiles will be reported along the centerline as a method of comparing different sail topologies. Centerline apex starts at the tack line attach point and ends at the perimeter cord along the center of the hypotenuse edge. For example, the tack line and the shear compliant border are both included in the centerline measurement. 


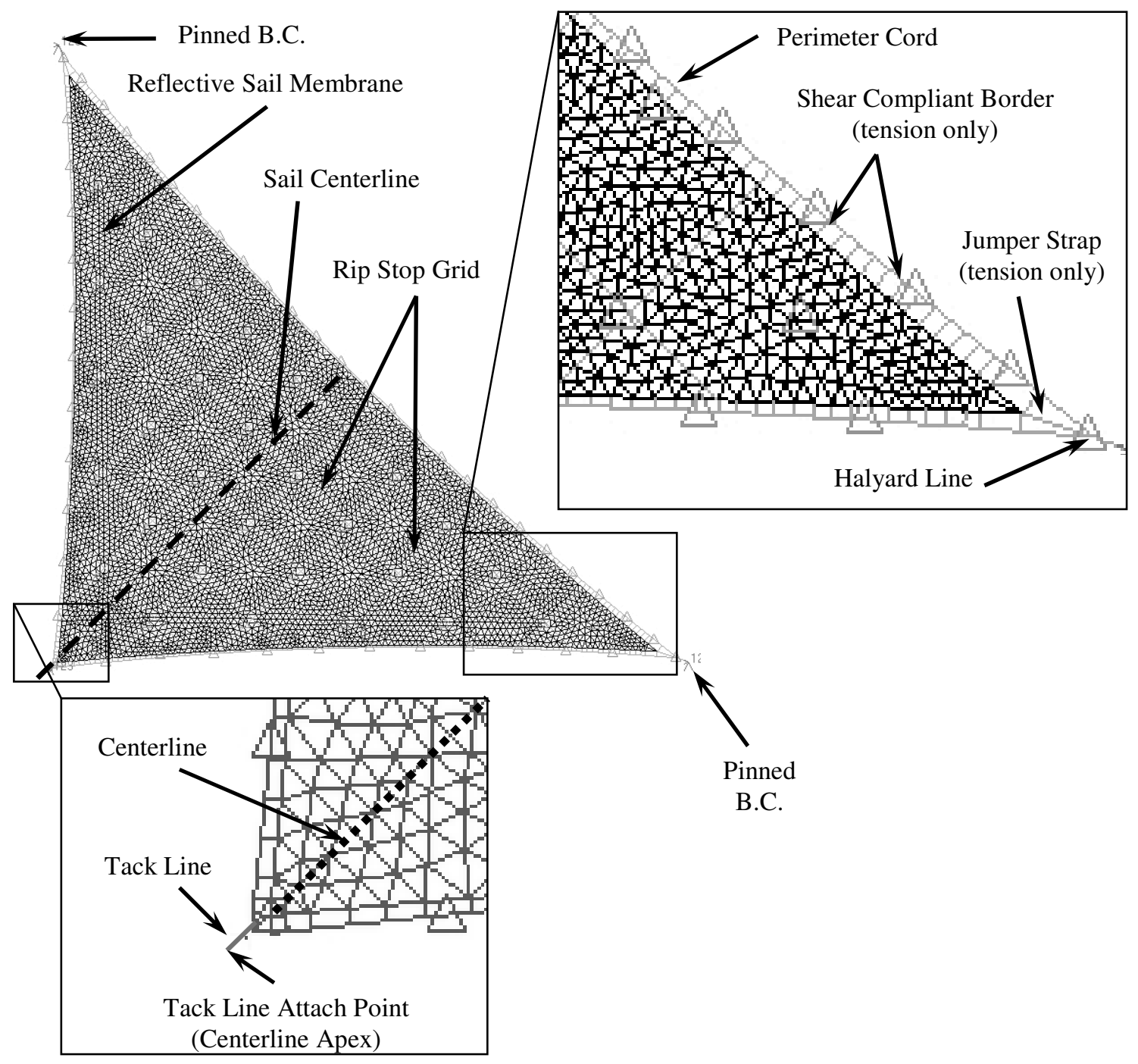

Figure 3. Details of the NASTARAN FEM components

It should be noted that a uniform solar pressure was used throughout finite element modeling. In reality, however, solar pressure acting on a curved non-planar sail is not uniform because the pressure is slightly different for each structural element depending on the local slope of each element. However, for a very shallow sail billow as observed in this investigation, this difference in pressure is considered a secondary effect and is neglected. For example, the maximum change in solar pressure on a structural element due to local element slope is only $0.4 \%$ for a $35^{\circ}$ off-normal solar incidence.

Accuracy of the sail topologies predicted by this FEM is driven mostly by the presence of local buckling in the structural elements. Element buckling is a numerically unstable occurrence that causes RMS error in the shape model to increase as the buckled elements radically change slope from one analysis to the next as discussed previously. Regions of buckled elements are an indication that membrane wrinkling is present, but these regions are not a true prediction of wrinkle location or geometry. The Penalty Parameter Modified Constitutive Law ${ }^{16,6}$ must be used to accurately predict the location of wrinkled sail regions and bending stiffness must be included to accurately predict wrinkle geometry. Temperature predictions from the shape model are driven down by a significant amount of element buckling because element temperatures are sensitive to small changes in element slope. Local sail shape should be accounted for if a more accurate prediction of thermally-induced sail topology and performance is desired than is provided in this investigation. However, the sail area affected by local element buckling is estimated to never exceed about $5 \%$ of the total sail area throughout this investigation. 


\section{Thermal Radiation Subroutine}

A thermal radiation subroutine was developed by the author using the MATLAB code to calculate sail temperature distribution for an FEM predicted sail surface topology. The subroutine calculates the temperature of each flat FEM structural element using Eqn. 4 derived previously. Heat conducted between elements is assumed negligible when compared to the rate at which heat is absorbed into and emitted from the thin membrane material $(3.58 \mu \mathrm{m})$ in the near-zero temperature environment of space.

User of the subroutine defines several solar parameters that influence sail temperature. First, direction of the sun-line is defined in spherical coordinates by $\gamma$ and $\varphi$ as indicated in Fig. 4. It is important to note that for a flat sail, $\varphi$ would have no effect sail temperature. But, for a non-planar sail such as considered in this investigation, $\varphi$ is critical to properly defining the solar incidence on the sail. The user also defines sail surface optical properties including absorptivity, sun-side emissivity, and backside emissivity.

The most critical function of the thermal radiation subroutine is determining orientation of the triangular structural elements with respect to the sun-line. The subroutine achieves this calculation by first arbitrarily choosing any two vectors of the same origin defined using the three nodes that compose a given triangular element. Fig. 4 depicts these vectors $\mathbf{k}$ and $\mathbf{m}$ with reference to a typical element. The element normal vector is then calculated through the cross product of these two vectors given as

$$
\mathbf{m} \times \mathbf{k}=\mathbf{n}
$$

It should be noted that the order in which nodes are numbered on a certain element in the FEM (clock-wise or counter-clockwise) determines initial direction of the element normal vector calculated in the subroutine (positive or negative z-direction). Therefore, special care was taken in the code to ensure that the each element normal is of the same sense, i.e., negative z-direction.

Projection of the element normal vector onto the sun-line vector is then determined through the following dot product:

$$
\mathbf{n} \cdot \mathbf{S}=\cos \theta
$$

Temperature of a specific element is then calculated by substituting $\cos \theta$ from Eqn. 6 into Eqn. 4. This approach of projecting each element normal vector onto the sun-line vector bounds the local incidence angle, $\theta$, within $-90^{\circ}$ and $90^{\circ}$. This limitation is well satisfied throughout this study.

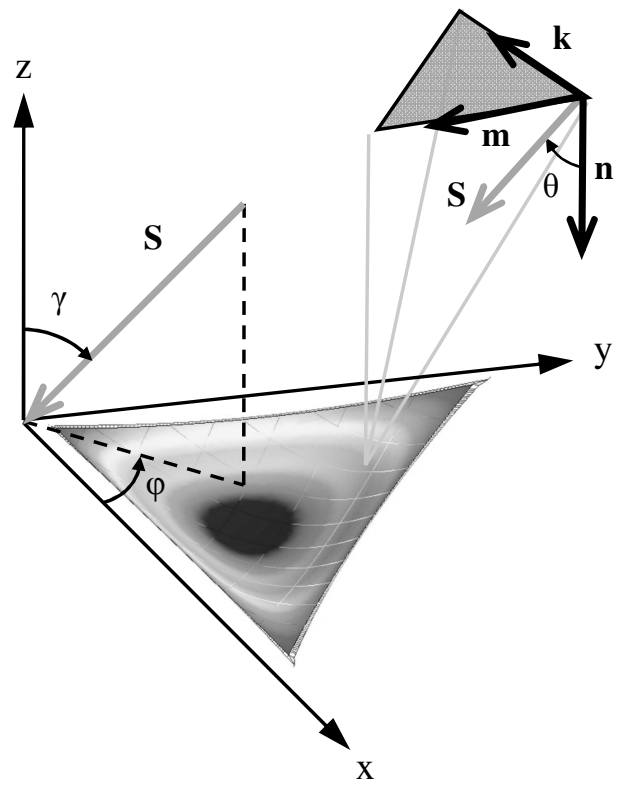

Figure 4. Vector algebra used in the thermal radiation subroutine to predict structural element temperatures 
Note that temperature of the 1D rip stop elements can not be predicted using the previous approach. Therefore rip stop element temperatures were approximated by averaging the temperature of surrounding triangular membrane elements. Such an approximation is reasonable for a steady-state thermal-radiation model such as this because the rip stop lines are actually embedded between layers of membrane material. Therefore, conduction would be the dominant method of heat transfer to the rip stop material.

Shear compliant border temperature also can not be predicted using the vector algebra approach previously discussed. While 1D elements provide a reasonable prediction of shear border mechanical performance for this particular sail configuration, they do not provide for a detailed prediction of the local shear border geometry; this geometry is needed to accurately determine shear border temperature. The complex shear compliant border geometry is dominated by two interdependent wrinkling patterns illustrated in Fig. 5. The first is a high wavelength, low amplitude uniform pattern manufactured into the border. The second is a less predictable lower wavelength, high amplitude pattern induced by excessive strain mismatch between the perimeter cord and sail membrane.

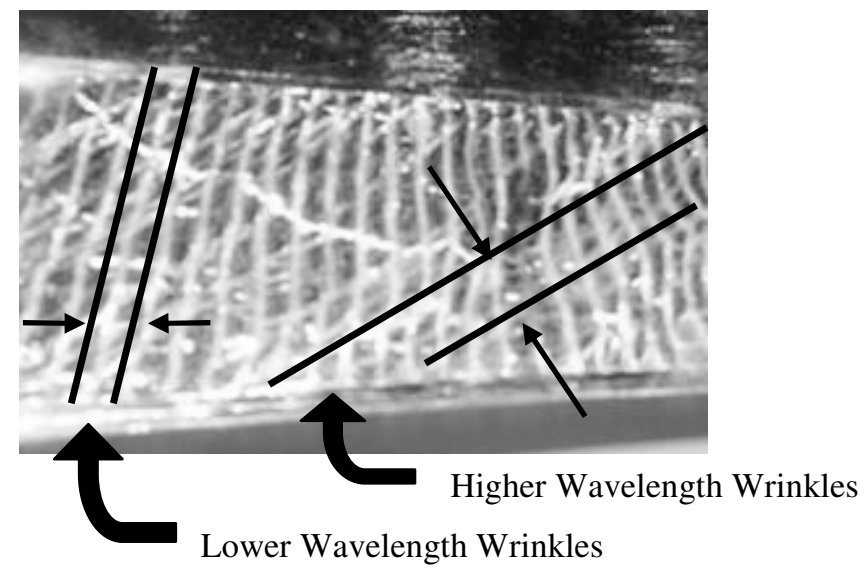

Figure 5. Deformation of the shear compliant border in a 1-g environment

Another complexity in predicting shear compliant border temperature arises in the fact that portions of the border material are not coated with aluminum. In reality, the drastic difference in reflectivity between coated and uncoated border regions would cause extreme non-uniform heating along the border. For this investigation the optical effect of the partially uncoated border will be qualitatively approximated as an introduced $1 \%$ transmissivity. From a thermal perspective, this trasmissivity corresponds to an inverse change in absorptivity of 0.01 that leads to a localized reduction in sail temperature. While one may expect this small change in absorptivity to have a minimal reduction in temperature, this is not the case. In fact, the shear border was predicted $10{ }^{\circ} \mathrm{C}$ cooler than the reflective sail membrane for this small reduction in absorptivity under a $35^{\circ}$ off-normal solar incidence. However, it was discovered that a temperature gradient even larger than $-10{ }^{\circ} \mathrm{C}$ such as $-25^{\circ} \mathrm{C}$ has a negligible effect on global sail shape (less than $0.1 \%$ change in maximum billow depth). Therefore, this approximation of border temperature is determined to be adequate for this investigation.

\section{E. IODA-Sail}

The final step in the shape model analysis procedure is to predict the effects of sail shape changes on sail performance. IODA-Sail ${ }^{17}$ is a software tool developed by SRS Technologies for the purpose of performing a high fidelity calculation of the sailcraft thrust vector magnitude, orientation, CP, and torques for certain FEM predicted surface topologies. The IODA-Sail user defines sail geometry by uploading a text file containing FEM node coordinates, node displacements, and element node numbers. The user also defines specific solar parameters and optical properties such as solar angle, solar flux, surface reflectivity, absorptivity, front-side emissivity, and backside emissivity. Force components accounted for in the thrust and torque calculations include those due to power diffusely reflected from, absorbed into, and emitted from the sail.

\section{F. Validation}

As mentioned in the introduction, a monumental effort has recently been dedicated to validating solar sail technologies. ${ }^{18}$ Such validation tests include the following: thermal, deployment in vacuum, static, and modal. While a great deal was learned about the technology throughout, these tests exposed many of the complexities associated with developing novel solar sail technologies. 
For example, thermal testing at GRC attempted to characterize the sail temperature for varying solar angles much like what is being done analytically in this investigation. This validation test revealed the difficulty in obtaining reliable temperature data of a membrane material.

Static and dynamic characteristics of solar sails need to be validated in a space-based environment to ensure future mission success. However, duplicating the light, on-orbit solar pressure loads is an impossible task in a gravity environment. Therefore finite element models must be developed with terrestrial load conditions, validated with ground test data, then modified to analyze on-orbit scenarios.

For this investigation, static deformation predicted by the FEM will be validated with static shape measurements taken of the $\mathrm{S}^{4}$ system ${ }^{15}$ during testing at the Space Power Facility in Sandusky, OH, conducted by a team from ATK, SRS, and LaRC. Test engineers utilized photogrammetry (PG) to gather shape data. 3D coordinates of one sail quadrant were measured at 90 retro-reflective targets bonded to the sail surface. Precision of the measured coordinates was $\pm 2 \mathrm{~mm}$, and accuracy was dictated by a calibration device used in the photogrammetry technique.

The FEM was modified slightly to accommodate ground-based load conditions. For example, 90 point mass elements (CONM) were added to the sail surface to account for the retro-reflective targets. The solar pressure load in the FEM was replaced with a 1-g load. Pre-tension was increased from $1 \mathrm{~N}$ to $26.7 \mathrm{~N}$, the estimated force authority of the negator springs attached to the two halyard line ends. It was discovered by test engineers that this pre-tension load varied slightly throughout the testing sequence. ${ }^{15}$ And it has been previously determined by the authors as well as by others ${ }^{19}$ that sail shape is sensitive to variations in magnitude of the halyard line load and location of the halyard attach points.

FEM data was compared to PG coordinates at 42 of the 90 points. Coordinate systems of the two data sets were matched at the sail origin indicated by point $A$ in Fig. 6 . This figure compares the sail deflection contours between the PG measurements and the FEM predictions. Notice that the maximum FEM billow depth differed from that of the PG by $13.1 \mathrm{~cm}$ or $24 \%$. The FEM predicted depth is $68.66 \mathrm{~cm}$, and the PG measured depth is $55.56 \mathrm{~cm}$. RMS error between the two topologies was calculated to be $9.40 \mathrm{~cm}$ or $17 \%$ of maximum PG billow depth. It is important to note that the overall topology predicted by the FEM seems to match that of the PG data fairly well as evidenced by nearly identical deflection contours illustrated in Fig. 6.

A great deal of the variations discovered between the PG data and FEM results are attributed to boundary condition uncertainty during sail testing. Two boundary conditions that were found to have a significant impact on sail shape were the halyard line load and the location of the two halyard line attach points. Considering the complexities of this highly nonlinear structure, these validation results institute confidence in the FEM.
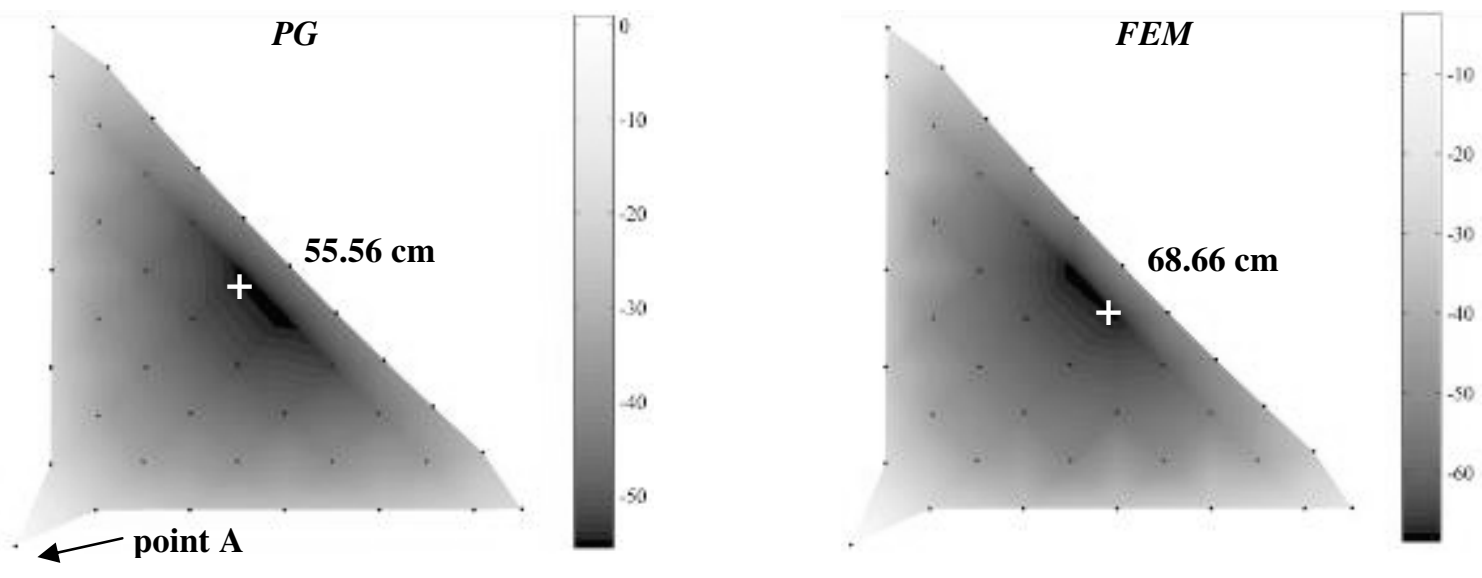

Figure 6. Comparison of deflection contours between PG and FEM

\section{Results}

\section{A. Sail Temperature and Shape Effects}

Sail temperature and topology were predicted according to the influence of four distinct on-orbit thermal scenarios. The first is a normal solar incident sun line $\left(\gamma=0^{\circ}\right)$. (See Fig. 4 for a geometric definition of $\gamma$ and $\varphi$.) The second is a $35^{\circ}$ off-normal $\left(\gamma=35^{\circ}\right), 45^{\circ}$ off-axis $\left(\varphi=45^{\circ}\right)$ solar incidence. Thirdly, a $35^{\circ}$ off-normal, on-axis $\left(\varphi=0^{\circ}\right)$ solar incidence was investigated. And finally, thermal effects were predicted according to a $35^{\circ}$ off-normal, $22.5^{\circ}$ off-axis $\left(\varphi=22.5^{\circ}\right)$ solar incidence. 
During the investigation of these thermal cases a discrepancy was discovered between the CTE of the membrane material, CP1, and the rip stop material, Kevlar. Such a discrepancy was found to cause extreme thermally-induced strains for small temperature gradients applied to the sail. Banik ${ }^{11}$ studied details of these effects in a separate investigation. For the majority of this investigation, the CTE of both materials was matched as will most likely be the case for a final sail design.

First, FEM predicted out-of-plane sail deflection contours are shown in Fig. 7 due to a normal solar incidence before a temperature load is applied. For this topology, one might expect the sail to be slightly hotter at the center and cooler near the edges because the local solar incidence angle is nearest $0^{\circ}$ at the point of maximum billow and non-zero at the sail edges. Furthermore, the temperature variation across the sail should be small for the shallow billow of $5.72 \mathrm{~mm}$ predicted for this solar incidence. The temperature distribution predicted by the thermal radiation subroutine shown in Fig. 8 indeed verifies these expectations as the temperature varies from a $0.0001{ }^{\circ} \mathrm{C}$ at the sail center to $-0.0002{ }^{\circ} \mathrm{C}$ at the sail edges. Position of these temperature extremes are indicated by crosses in the figure. It turns out that strains thermally-induced by this temperature distribution had a negligible effect on sail shape.

It should be noted that Fig. 8 does not represent absolute sail temperatures but rather the temperatures scaled to $25{ }^{\circ} \mathrm{C}$ room temperature, i.e., the starting point of thermal contraction/expansion. In fact, all temperatures predicted in this study are scaled to room temperature because the sail was designed to operate at the assembly room temperature such that no thermal expansion or contraction would take place for a normal solar incidence. ${ }^{20}$ To satisfy this design parameter exactly, surface reflectivity of the sail membrane was defined to be 0.926582 , a value that lies within the range measured by sail designers.

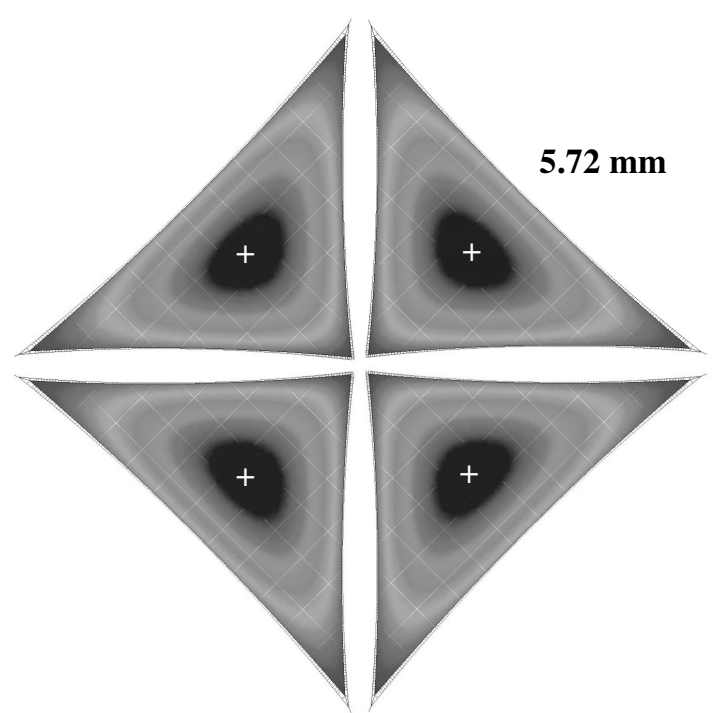

Figure 7. FEM deflection contours due to normal solar incidence, no thermal load

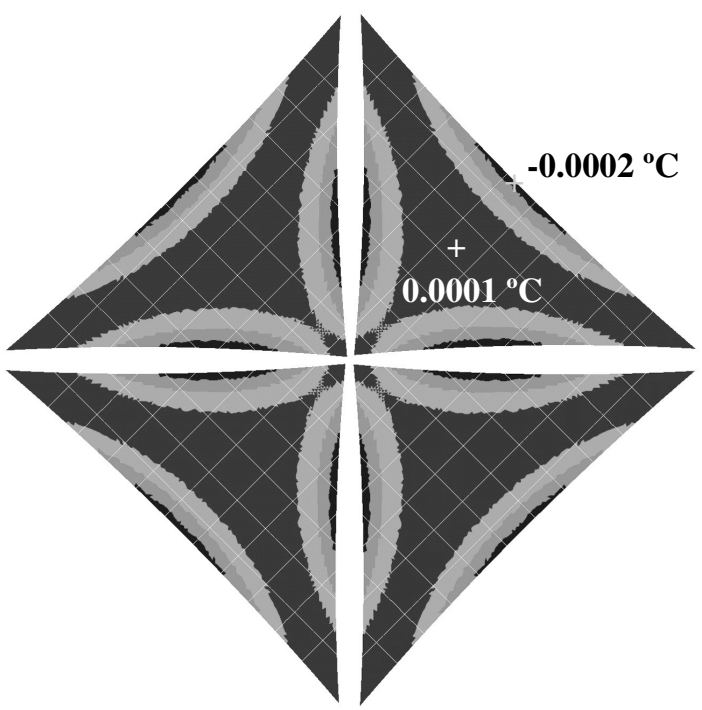

Figure 8. Temperature contours due to normal solar incidence

Both the initial curved sail shape and the uniform "flat-sail" temperature were predicted for a $35^{\circ}$ off-normal solar incidence. This non-planar sail shape and uniform sail temperature will provide a baseline for comparison between the non-uniform thermal effects to be presented later.

The out-of-plane sail deflection contours due to a $35^{\circ}$ off-normal incidence $\left(\gamma=35^{\circ}\right)$ exactly matched those due to a normal solar incidence shown in Fig. 7. The maximum billow depth however is reduced significantly from the normal solar incidence $(5.72 \mathrm{~mm})$ to the $35^{\circ}$ off-normal incidence $(3.97 \mathrm{~mm})$ because the magnitude of solar pressure acting normal to the sail is proportional to the cosine squared of the incidence angle. The uniform change in sail surface temperature due to the transition from the normal solar incidence to the $35^{\circ}$ off-normal was $-14.50^{\circ} \mathrm{C}$ for a flat-sail not subjected to solar pressure. When this uniform temperature gradient was applied to the FEM, maximum sail billow was reduced by $4.0 \%$ from $3.97 \mathrm{~mm}$ to $3.82 \mathrm{~mm}$.

Non-uniform sail temperature distributions were then predicted for the three $35^{\circ}$ off-normal cases and used to generate final sail topologies. For all three cases one would expect the sail to be slightly hotter near the far edges of the sail and cooler near the "shaded" regions. In fact this was the case. Also the temperature distribution should be symmetric about the axes coincident with each of three respective sun-lines. This proved to be the case for two of the three cases as evidenced in the following results. 
For the $35^{\circ}$ off-normal $\left(\gamma=35^{\circ}\right), 45^{\circ}$ off-axis $\left(\varphi=45^{\circ}\right)$ solar incidence case, the predicted temperature distribution follows expected trends as visually represented by the temperature contours in Fig. 9. Notice the contours are symmetric about the sun-line axis. Also notice that for an extremely shallow $3.97 \mathrm{~mm}$ maximum deflection, the maximum temperature gradient occurring in quadrant one $(\mathrm{Q} 1)$ is $0.2^{\circ} \mathrm{C}$ ranging from $-14.42{ }^{\circ} \mathrm{C}$ near the far sail edges to $-14.62{ }^{\circ} \mathrm{C}$ near the shaded sail regions. Position of these temperature extremes is indicated by crosses in Fig. 9. The remaining three quadrants show a similar temperature gradient as is visible in this figure. By comparing the pressure only deflection contours in Fig. 7 with the non-uniform temperature contours in Fig. 9, one can validate the effect of the spatial rate of sail slope change on sail temperature.

Notice the temperature gradient across the sail is much higher for this off-normal case than for the normal case discussed previously. This can be numerically verified upon inspection of Eqn. 4. In this equation, the cosine of the local element incidence angle $\theta$ is the variable that drives temperature variation. As is well known, the slope of a cosine curve rapidly decreases as the function approaches $0^{\circ}$. Therefore, the same change in sail slope between two different solar incidence angles of $0^{\circ}$ and $35^{\circ}$ will produce a drastically different temperature gradient.

Several conclusions can be drawn from the thermally-induced changes in sail shape caused by this off-normal, off-axis solar incidence case. Fig. 10 shows both the exaggerated difference in sail deformation (20000x) and the corresponding deflection contours between a sail loaded with the uniform, $-14.5^{\circ} \mathrm{C}$, temperature and a sail loaded with the non-uniform temperature distribution shown in Fig. 9. Fig. 10 clearly shows that sail topology is indeed influenced by this non-uniform temperature distribution.

Intuition would suggest that a non-uniform temperature distribution would cause a sail to sag more on the hotter side and less on the cooler side. However, the out-of-plane deflection contours in Fig. 10 reveal a much different trend, i.e., the hotter side of the sail sags less and the colder side sags more. This can be explained by detailed examination of the exaggerated deformations shown in the same figure. Notice that the in-plane deformation of the sail perimeter cord is of the same order of magnitude as the out-of-plane deformation of the sail membrane. And when the temperature contours in Fig. 9 are compared to these deformations in Fig. 10, it is apparent that the hottest regions of the sail correspond to the regions of greatest in-plane expansion. This in-plane expansion forces the nearby perimeter cord away from the sail membrane, increasing the tension of the local membrane region. A local increase in membrane tension causes the membrane to deflect in the positive out-of-plane direction, corresponding to a counterintuitive shallower billow depth in the warmer sail regions. The colder regions react similarly albeit in opposite directions.

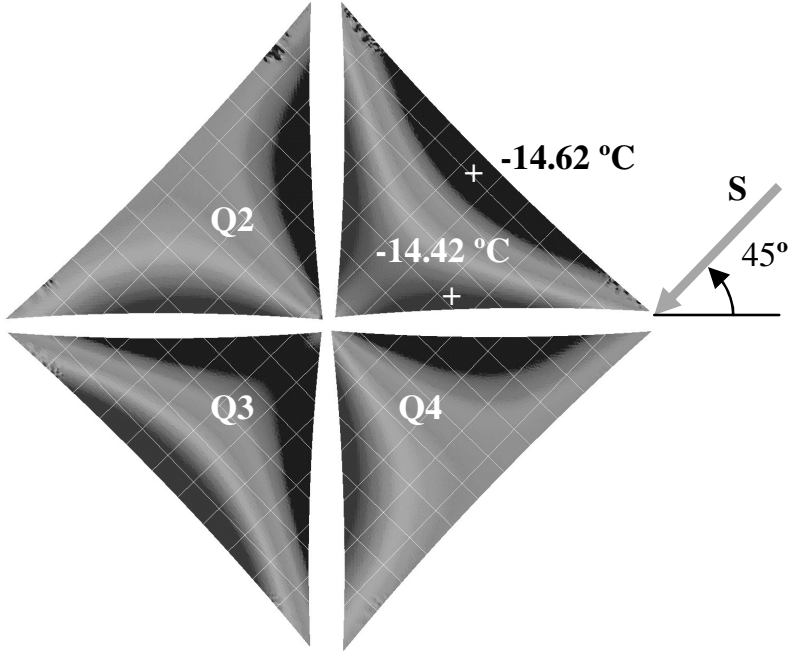

Figure 9. Temperature contours due to $35^{\circ}$ offnormal, $45^{\circ}$ off-axis solar incidence $\left(\gamma=35^{\circ}, \varphi=45^{\circ}\right)$

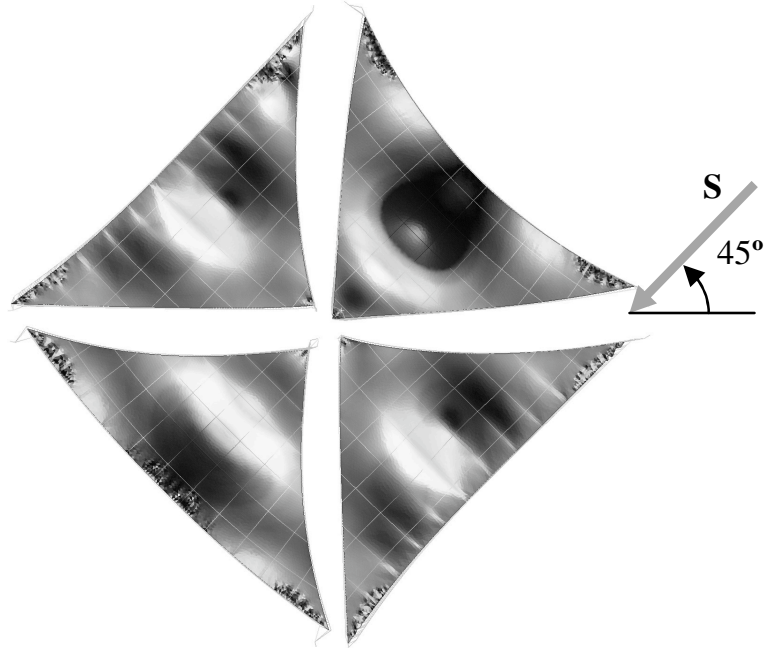

Figure 10. FEM exaggerated deformations due to the transition from a uniform to a non-uniform temperature load $\left(\gamma=35^{\circ}, \varphi=4^{\circ}\right)$

For this solar incidence case, the change in maximum billow depth between a sail with a uniform thermal load $\left(-14.50{ }^{\circ} \mathrm{C}\right)$ and a sail with a non-uniform thermal load ranged from $0.8 \%$ to $2.7 \%$ as listed in Table 1. Interestingly, the $2.7 \%$ change in billow depth (Q1) caused by a $0.2{ }^{\circ} \mathrm{C}$ temperature gradient is on the same order of magnitude as the $4.0 \%$ change caused by the uniform $-14.50^{\circ} \mathrm{C}$ gradient discussed previously. Changes in maximum sail billow depth for the other three quadrants show similar trends but of slightly less magnitude than Q1 as listed in Table 1. 
Table 1. FEM maximum deflection results due to three off-normal solar incidence cases. Non-uniform temperature is the final converged shape model result.

\begin{tabular}{|c|c|c|c|c|c|c|c|}
\hline & & \multicolumn{2}{|c|}{$\gamma=35^{\circ}, \varphi=45^{\circ}$} & \multicolumn{2}{|c|}{$\gamma=35^{\circ}, \varphi=0^{\circ}$} & \multicolumn{2}{|c|}{$\gamma=35^{\circ}, \varphi=22.5^{\circ}$} \\
\hline & & $\begin{array}{c}\text { Max Defl. } \\
(\mathrm{mm})\end{array}$ & Difference & $\begin{array}{c}\text { Max Defl. } \\
(\mathrm{mm})\end{array}$ & Difference & $\begin{array}{c}\text { Max Defl. } \\
(\mathrm{mm})\end{array}$ & Difference \\
\hline & No Temp & 3.975 & - & 3.975 & - & 3.975 & - \\
\hline \multirow[t]{4}{*}{ Q1 } & Uniform Temp & 3.818 & $4.0 \%$ & 3.818 & $4.0 \%$ & 3.818 & $4.0 \%$ \\
\hline & Non-uniform Temp & 3.922 & $2.7 \%$ & 3.904 & $2.3 \%$ & 3.919 & $2.7 \%$ \\
\hline & & Overall & $1.3 \%$ & Overall & $1.8 \%$ & Overall & $1.4 \%$ \\
\hline & No Temp & 3.975 & - & 3.975 & - & 3.975 & - \\
\hline \multirow[t]{2}{*}{ Q2 } & Uniform Temp & 3.818 & $4.0 \%$ & 3.818 & $4.0 \%$ & 3.818 & $4.0 \%$ \\
\hline & Non-uniform Temp & 3.848 & $0.8 \%$ & 3.782 & $0.9 \%$ & 3.813 & $0.1 \%$ \\
\hline & & Overall & $3.2 \%$ & Overall & $4.9 \%$ & Overall & $4.1 \%$ \\
\hline \multirow{3}{*}{ Q3 } & No Temp & 3.975 & - & 3.975 & - & 3.975 & - \\
\hline & Uniform Temp & 3.818 & $4.0 \%$ & 3.818 & $4.0 \%$ & 3.818 & $4.0 \%$ \\
\hline & Non-uniform Temp & 3.754 & $1.7 \%$ & 3.782 & $0.9 \%$ & 3.759 & $1.5 \%$ \\
\hline & & Overall & $5.6 \%$ & Overall & $4.9 \%$ & Overall & $5.4 \%$ \\
\hline \multirow{3}{*}{ Q4 } & No Temp & 3.975 & - & 3.975 & - & 3.975 & - \\
\hline & Uniform Temp & 3.818 & $4.0 \%$ & 3.818 & $4.0 \%$ & 3.818 & $4.0 \%$ \\
\hline & Non-uniform Temp & 3.848 & $0.8 \%$ & 3.907 & $2.3 \%$ & 3.879 & $1.6 \%$ \\
\hline & & Overall & $3.2 \%$ & Overall & $1.7 \%$ & Overall & $2.4 \%$ \\
\hline
\end{tabular}

Billow profiles measured along the sail centerline were compared to give another perspective into these thermally-induced sail shape changes. It should be noted that sail topologies asymmetric about this centerline are not well represented by these profiles. Specifically, Q2 and Q4 topologies are asymmetric for this incidence case. Nevertheless, Fig. 11 shows all billow profiles for this off-normal, $45^{\circ}$ off-axis solar incidence. Notice that the difference between these profiles is deterministic especially between the uniform temperature profile and the profile predicted for Q1. Note from Table 1 that Q1 is the quadrant determined to have the greatest change in maximum billow depth and Fig. 11 indicates a similar result.

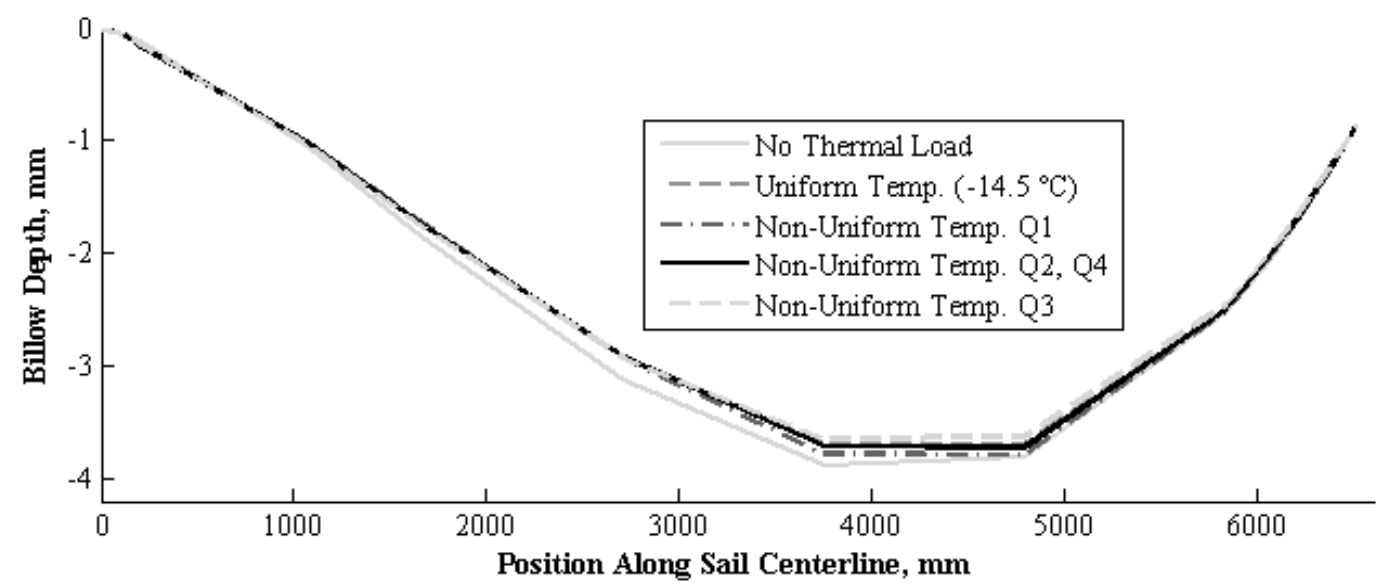

Figure 11. Comparison of shape model billow profiles $\left(\gamma=35^{\circ}, \varphi=45^{\circ}\right)$. Note that the abrupt changes in slope are due to a low number of discrete data points. These profiles are not indicative of a true, smooth sail shape.

Next, the $35^{\circ}$ off-normal $\left(\gamma=35^{\circ}\right)$, on-axis $\left(\varphi=0^{\circ}\right)$ solar incidence case was investigated. The temperature distribution predicted for this case follows similar trends to that of the $45^{\circ}$ off-axis case as represented by the temperature contours in Fig. 12. Notice the temperature distribution is effectively rotated $45^{\circ}$ clockwise from that of the first case as expected for a sun-line rotated accordingly. The temperature distribution is again symmetric about 
the sun-line axis with the shaded sail regions being cooler and the far sail edges being warmer. The temperature gradient across each of the four quadrants was an identical $0.17^{\circ} \mathrm{C}$, slightly less than maximum predicted for the previous incidence case. Actual sail temperatures ranged from $-14.43{ }^{\circ} \mathrm{C}$ to $-14.60{ }^{\circ} \mathrm{C}$ across $\mathrm{Q} 2$ and $\mathrm{Q} 3$. And they ranged from $-14.41{ }^{\circ} \mathrm{C}$ to $-14.58^{\circ} \mathrm{C}$ across Q1 and Q4. Exaggerated changes in sail shape and deflection contours shown in Fig. 13 also show similar trends to those of the $45^{\circ}$ off-axis case from Fig. 10.

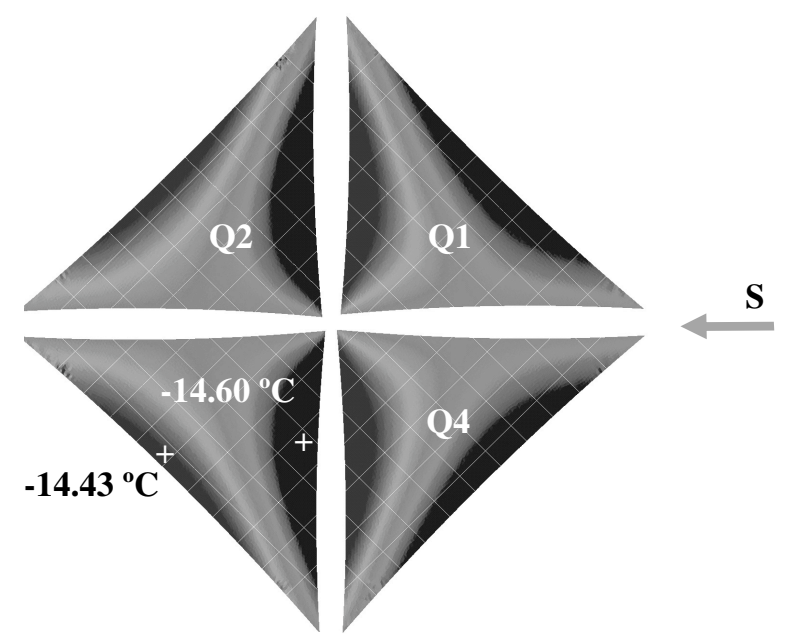

Figure 12. Temperature contours due to $35^{\circ}$ offnormal, on-axis solar incidence $\left(\gamma=35^{\circ}, \varphi=0^{\circ}\right)$

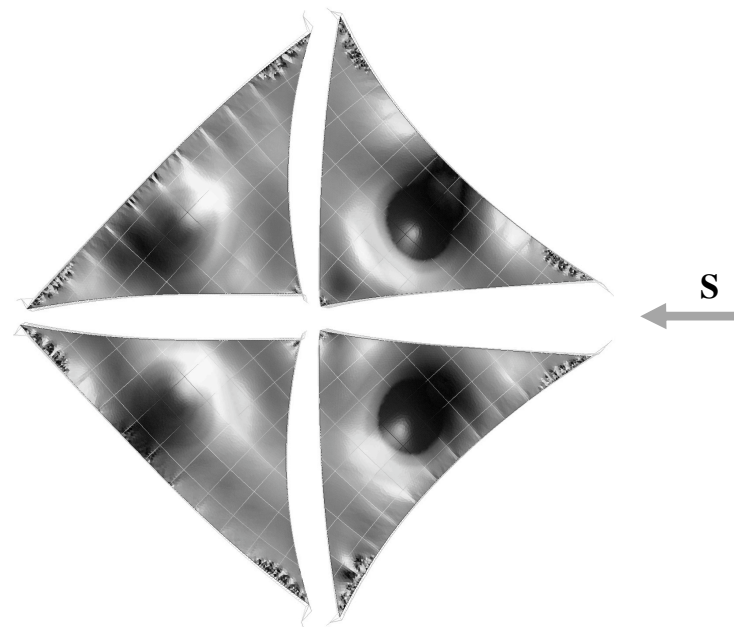

Figure 13. FEM exaggerated deformations due to the transition from a uniform to a non-uniform temperature load $\left(\gamma=35^{\circ}, \varphi=0^{\circ}\right)$

For this on-axis solar incidence case, the change in maximum billow depth between a sail with uniform thermal load and a sail with a non-uniform thermal load ranged from $0.9 \%$ to $2.3 \%$ as listed in Table 1 . These changes are similar to those predicted for the previous $45^{\circ}$ off-axis solar incidence case.

Fig. 14 shows sail billow profiles predicted for this off-normal, on-axis solar incidence case. Again, sail shapes that are not symmetric about the sail centerline are not well represented by these profiles. In this case, none of the quadrants are symmetric. Therefore the billow profiles are not necessarily a good representation of the magnitude of thermally-induced changes in sail shape. Despite this fact, billow profiles in Fig. 14 show a definite change in sail shape especially between the uniform temperature induced profile and the non-uniform temperature induced profile for Q1 and Q4. Notice the rightward shift in maximum billow from the "No Thermal Load" profile to the "NonUniform Temp. Q1, Q4" profile. This shift is also verified in the out-of-plane deflection contours shown in Fig. 13 where a deeper billow is shown near the hypotenuse of both Q1 and Q4. Given the deflection contours in Fig. 13 and billow profiles in Fig. 14, perspective is gained into the magnitude of the thermal effects of an off-normal solar incidence on sail topology.

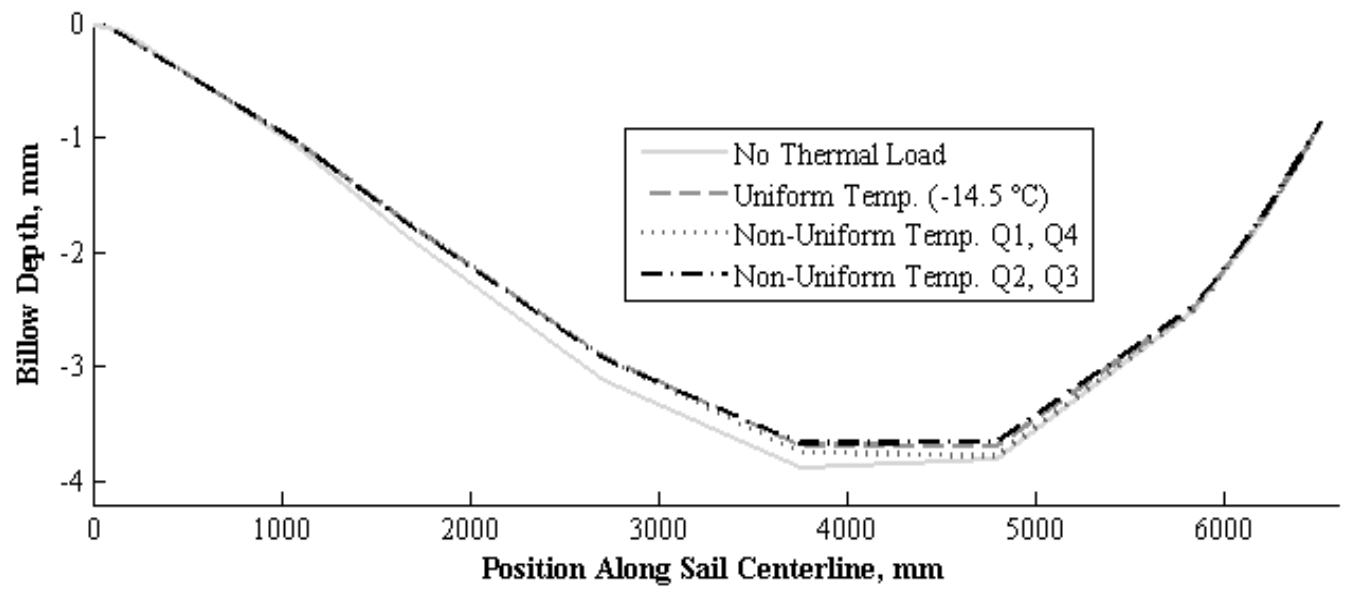

Figure 14. Comparison of shape model billow profiles $\left(\gamma=35^{\circ}, \varphi=0^{\circ}\right)$. Note that the abrupt changes in slope are due to a low number of discrete data points. Profiles are not indicative of a smooth sail shape. 
Finally, the $35^{\circ}$ off-normal $\left(\gamma=35^{\circ}\right), 22.5^{\circ}$ off-axis $\left(\varphi=22.5^{\circ}\right)$ solar incidence case was investigated. The temperature distribution predicted for this case differs from the other two in that it is not symmetric about the sunline axis. The temperature contours in Fig. 12 show that the distribution is not symmetric about the sun-line axis in contrast to the temperature contours reported for the previous two cases. These previous cases operate on geometrically symmetric sun-line axes. The third case, however, does not. Consequently, the temperature gradients across each of the four quadrants are different. The temperatures gradient across Q1 was measured to be $0.18^{\circ} \mathrm{C}$, $0.14{ }^{\circ} \mathrm{C}$ across Q2, $0.44{ }^{\circ} \mathrm{C}$ across Q3 and $0.13{ }^{\circ} \mathrm{C}$ across Q4. Fig. 15 shows the exact position of temperature extremes detected in $\mathrm{Q} 3,-14.27{ }^{\circ} \mathrm{C}$ to $-14.71^{\circ} \mathrm{C}$. Exaggerated changes in sail shape and deflection contours shown in Fig. 16 also show similar trends to those of the $45^{\circ}$ off-axis case and the on-axis cases from Fig. 10 and Fig. 13 respectively.

For this $22.5^{\circ}$ off-axis solar incidence case, the change in maximum billow depth between a sail with uniform thermal load and a sail with a non-uniform thermal load ranged from $0.1 \%$ to $2.7 \%$ as listed in Table 1 . These changes are of similar magnitude to those detected for the $45^{\circ}$ off-axis sun-line case and the on-axis case.

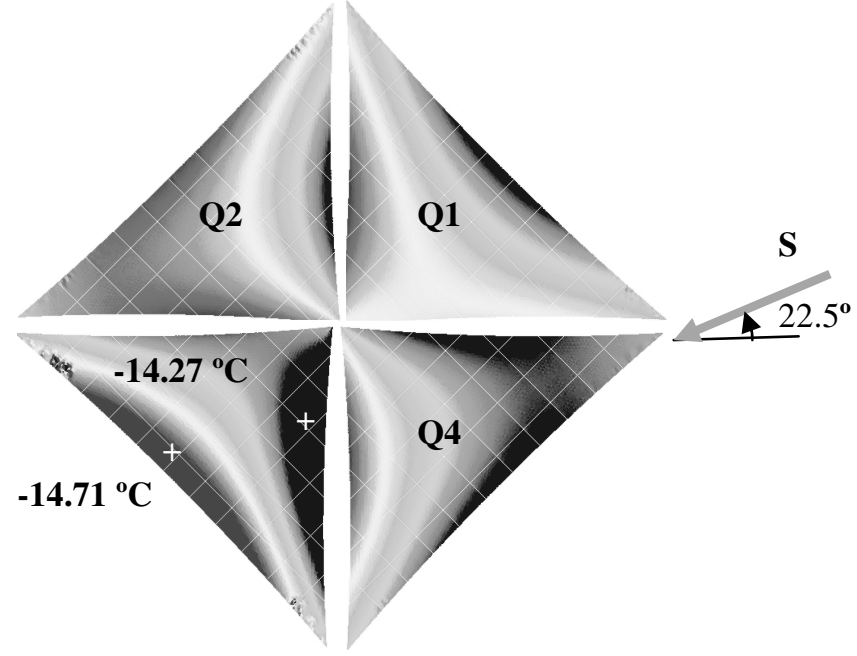

Figure 15. Temperature contours due to $35^{\circ}$ offnormal, $22.5^{\circ}$ off-axis solar incidence $\left(\gamma=35^{\circ}, \varphi=22.5^{\circ}\right)$

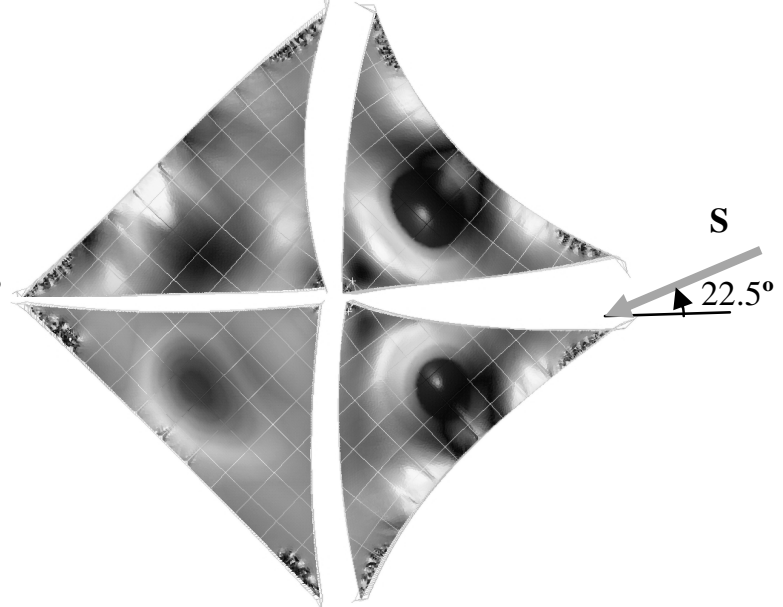

Figure 16. FEM exaggerated deformations due to the transition from a uniform to a non-uniform temperature load $\left(\gamma=35^{\circ}, \varphi=22.5^{\circ}\right)$

\section{B. Sail Performance Effects}

Solar sail thrust, torque, and CP were calculated for the previously determined sail surface topologies. Thrust and torque will be reported in non-dimensional form as defined by Derbes ${ }^{21}$. He non-dimensionalized the force coefficient $\mathrm{C}_{\mathrm{f}}$ as follows:

$$
\mathrm{C}_{\mathrm{f}}=\mathrm{F} /(\mathrm{P} \times \mathrm{A})
$$

He similarly non-dimensionalized the torque coefficient $\mathrm{C}_{\mathrm{m}}$ :

$$
\mathrm{C}_{\mathrm{m}}=\mathrm{M} /(\mathrm{P} \times \mathrm{A} \times \mathrm{L})
$$

The reference coordinate system used to report performance is the same as that used by ATK ${ }^{1}$ as shown in Fig. 17. Yaw is shown about the z-axis, pitch about the y-axis, and roll about the $\mathrm{x}$-axis as illustrated on a sailcraft and referenced to a typical spacecraft. 

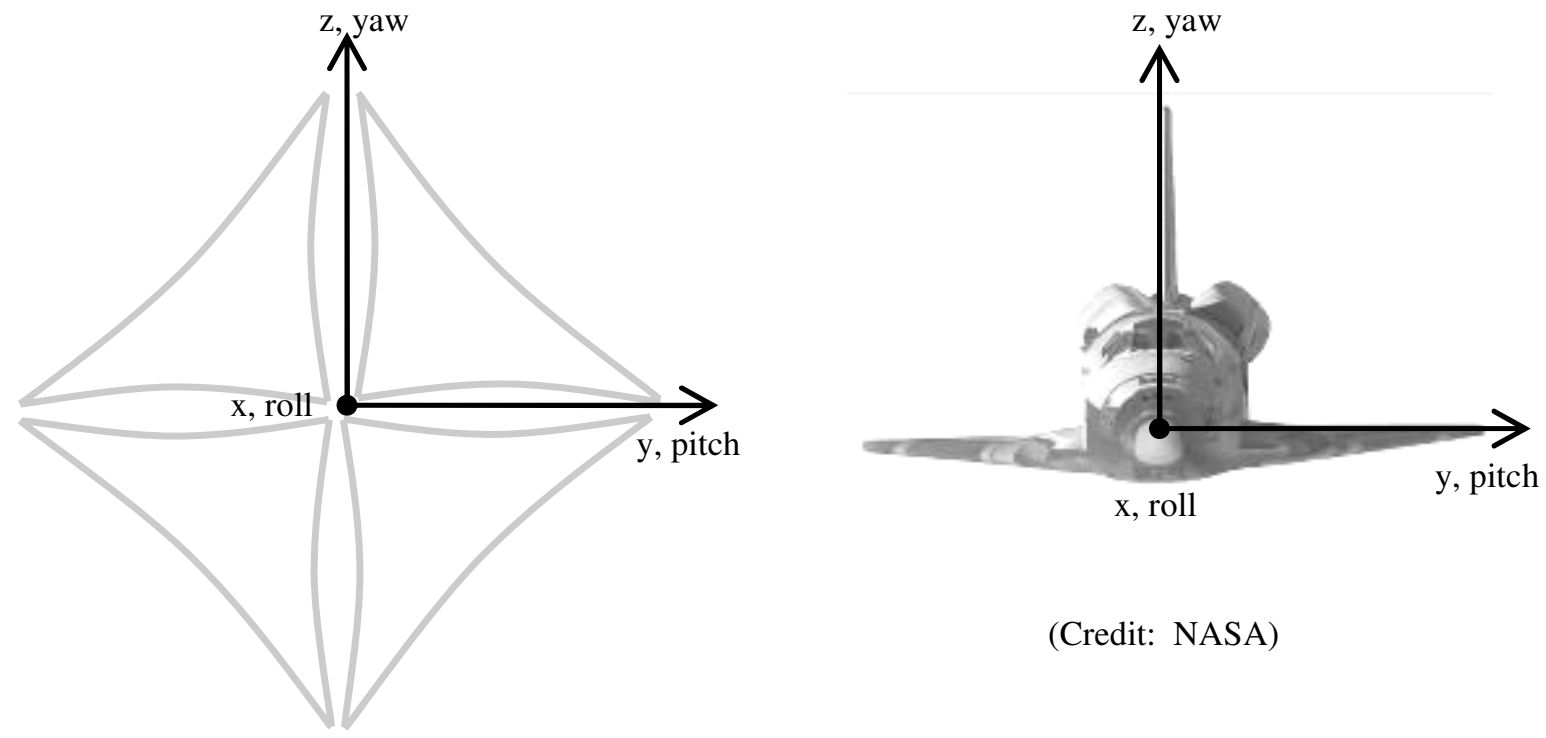

Figure 17. Reference coordinate system used in calculating solar sail performance

Performance values will first be presented due to the $35^{\circ}$ off-normal, $45^{\circ}$ off-axis solar incidence case $\left(\gamma=35^{\circ}\right.$, $\left.\varphi=45^{\circ}\right)$. No definitive roll torque $\left(\mathrm{C}_{\mathrm{mx}}\right)$ was detected from either the uniform or the non-uniform temperature loads. Roll torque was detected, however, on several of the individual sail quadrants, but once the full-system torque was summed, these individual torques cancelled each other as was expected for a sail topology symmetric about the sunline axis. By the way, this may not always be the case. For example if the sun-line, defined by $\varphi$, is incident at any position other than $0^{\circ}$ or $45^{\circ}$ (e.g. $22.5^{\circ}$ as in case three) then sail deflections will not be symmetric about the sunline. And since temperature distribution predicted for the $22.5^{\circ}$ off-axis case is asymmetric about the sun-line axis, sail deflections are also expected to be asymmetric. This proved to be the case as will be discussed in the following results.

In-plane torques were moderately influenced by the $45^{\circ}$ off-axis incidence case. For example, the pitch torque $\left(\mathrm{C}_{\mathrm{my}}\right)$ decreased by $4.28 \%$ from the no thermal load condition to the uniform thermal load condition as listed in Table 2. Yaw torque $\left(\mathrm{C}_{\mathrm{mz}}\right)$ decreased by the same measure. These identical pitch and yaw torques are expected for a sun-line that lies equidistant between the yaw and pitch axes. However, the pitch torque did change in a non-uniform manner when a non-uniform thermal was applied. For example, pitch torque increased by $1.37 \%$ while yaw torque increased by only $0.66 \%$. This non-uniform change in torque is attributed to the asymmetric sail topology induced by the non-uniform thermal load.

Measured changes in sail thrust due to this $45^{\circ}$ off-axis solar incidence case were found to be significantly less than sail torque changes. For example, none of the thrust coefficients in the $\mathrm{y}, \mathrm{z}$, and $\mathrm{x}$-directions changed by more than $0.12 \%$ when a uniform thermal load was applied to the sail. When a non-uniform thermal load was applied, changes were even less apparent. Thrust in the y-direction changed slightly while the remaining two thrust components remained the same.

Moderate changes in the sail CP were also detected. Notice from Table 2 that the $\mathrm{CP}$ shifted by $-3.00 \mathrm{~mm}$ in both the $y$ and z-directions during the transition from a flat-sail to a sail deformed out-of-plane by solar pressure. When a uniform thermal load was applied, the CP shifted back to the origin by $0.11 \mathrm{~mm}(3.67 \%)$ in both y and $\mathrm{z}$ directions. Finally, when a non-uniform thermal load was applied, the CP moved away from the origin by $0.02 \mathrm{~mm}$ $(0.69 \%)$ in the y-direction and by $0.04 \mathrm{~mm}(1.38 \%)$ in the z-direction.

Next, performance was predicted due to the thermal effects of the $35^{\circ}$ off-normal $\left(\gamma=35^{\circ}\right)$, on-axis $\left(\varphi=0^{\circ}\right)$ solar incidence. Similar to the $45^{\circ}$ off-axis incidence case, no changes in roll torque were detected for the on-axis case. The pitch torque also remained constant throughout the uniform and non-uniform thermal load scenarios. This is expected because the sun-line is coincident with the pitch axis therefore sail shape is also symmetric about the pitch axis. Yaw torque did change however. In fact, it decreased by $4.42 \%$ when a uniform thermal load was applied and increased by $0.73 \%$ when a non-uniform thermal load was applied. Such a trend is similar to that predicted for the previous, $45^{\circ}$ off-axis, solar incidence case but of slightly greater magnitude because asymmetries in sail shape within each quadrant are more pronounced within this case than within the $45^{\circ}$ off-axis case. 
Table 2. 20-meter full-system performance coefficients. (Percent change from the previous column is shown.)

\begin{tabular}{|c|c|c|c|c|c|}
\hline & \multicolumn{5}{|c|}{ a) $\gamma=35^{\circ} \varphi=45^{\circ}$} \\
\hline & Units & Flat-Sail & No Thermal Load & Uniform Temp & Non-uniform Temp \\
\hline $\mathrm{C}_{\mathrm{fy}}$ & - & - & -0.0494 & $-0.04934(-0.12 \%)$ & $-0.04935(0.02 \%)$ \\
\hline $\mathrm{C}_{\mathrm{fz}}$ & - & - & -0.0494 & $-0.04934(-0.12 \%)$ & -0.04934 \\
\hline $\mathrm{C}_{\mathrm{fx}}$ & - & -80.53 & -66.55 & $-66.47(-0.12 \%)$ & -66.47 \\
\hline $\mathrm{C}_{\mathrm{my}}$ & - & - & 0.002219 & $0.002124(-4.28 \%)$ & $0.002153(1.37 \%)$ \\
\hline $\mathrm{C}_{\mathrm{mz}}$ & - & - & -0.002219 & $-0.002124(-4.28 \%)$ & $-0.002138(0.66 \%)$ \\
\hline $\mathrm{C}_{\mathrm{mx}}$ & - & - & - & - & - \\
\hline $\mathbf{C P}_{\mathbf{y}}$ & $\mathrm{mm}$ & - & -3.00 & $-2.89(3.67 \%)$ & $-2.91(-0.69 \%)$ \\
\hline $\mathrm{CP}_{\mathrm{z}}$ & $\mathrm{mm}$ & - & -3.00 & $-2.89(3.67 \%)$ & $-2.93(-1.38 \%)$ \\
\hline
\end{tabular}

b) $\gamma=3^{\circ} \varphi=0^{\circ}$

\begin{tabular}{|c|c|c|c|c|c|}
\hline & Units & Flat-Sail & No Thermal Load & Uniform Temp & Non-uniform Temp \\
\hline $\mathrm{C}_{\mathrm{fy}}$ & - & - & -0.06987 & $-0.06958(-0.42 \%)$ & -0.06958 \\
\hline $\mathrm{C}_{\mathrm{fz}}$ & - & - & - & - & - \\
\hline $\mathrm{C}_{\mathrm{fx}}$ & - & -80.53 & -66.55 & $-66.47(-0.12 \%)$ & -66.47 \\
\hline $\mathrm{C}_{\mathrm{my}}$ & - & - & - & - & - \\
\hline $\mathrm{C}_{\mathrm{mz}}$ & - & - & -0.003145 & $-0.003006(-4.42 \%)$ & $-0.003028(0.73 \%)$ \\
\hline $\mathrm{C}_{\mathrm{mx}}$ & - & - & - & - & - \\
\hline $\mathrm{CP}_{\mathrm{y}}$ & $\mathrm{mm}$ & - & -4.24 & $-4.08(3.77 \%)$ & $-4.12(-0.98 \%)$ \\
\hline $\mathrm{CP}_{\mathrm{z}}$ & $\mathrm{mm}$ & - & - & - & - \\
\hline
\end{tabular}

c) $\gamma=35^{\circ} \varphi=22.5^{\circ}$

\begin{tabular}{|c|c|c|c|c|c|}
\hline & Units & Flat-Sail & No Thermal Load & Uniform Temp & Non-uniform Temp \\
\hline $\mathrm{C}_{\mathrm{fy}}$ & - & - & -0.06429 & -0.06429 & $-0.06426(-0.05 \%)$ \\
\hline $\mathbf{C}_{\mathrm{fz}}$ & - & - & -0.02673 & $-0.0267(-0.11 \%)$ & -0.0267 \\
\hline $\mathrm{C}_{\mathrm{fx}}$ & - & -80.53 & -66.55 & $-66.47(-0.12 \%)$ & -66.47 \\
\hline $\mathrm{C}_{\mathrm{my}}$ & - & - & -0.001205 & $-0.001146(-4.90 \%)$ & $-0.001161(1.31 \%)$ \\
\hline $\mathrm{C}_{\mathrm{mz}}$ & - & - & 0.002895 & $0.00277(-4.32 \%)$ & $0.002793(0.83 \%)$ \\
\hline $\mathrm{C}_{\mathrm{mx}}$ & - & - & - & - & 8.818E-6 \\
\hline $\mathbf{C P}_{\mathrm{y}}$ & $\mathrm{mm}$ & - & -2.82 & $-2.72(-3.55 \%)$ & $-2.75(1.10 \%)$ \\
\hline $\mathrm{CP}_{\mathrm{z}}$ & $\mathrm{mm}$ & - & -2.71 & $-2.61(-3.69 \%)$ & $-2.64(1.15 \%)$ \\
\hline
\end{tabular}

Sail thrust changed by a similar measure to the first case. Thrust in the y-direction decreased by $0.42 \%$ when a uniform temperature was applied. No change in thrust was detected in the z-direction because that axis lies perpendicular to the sun-line. The x-direction thrust decreased by $0.12 \%$ which is the same as predicted for the first case. This verifies that the normal thrust component is not affected by the angle $\varphi$ which dictates either an off-axis or on-axis solar incidence.

Similar changes in the sail CP were detected for this solar incidence case than the first. Notice from Table 2 that the CP shifted away from the origin by $4.24 \mathrm{~mm}$ in the y-direction when solar pressure was applied, more than predicted for the $45^{\circ}$ off-axis case. However, the z-direction CP did not shift for this solar incidence, as expected for a sun-line perpendicular to the z-axis. When a uniform thermal load was applied, the CP shifted back toward the origin by $0.16 \mathrm{~mm}(3.77 \%)$ along the y-axis, slightly greater than calculated for the first solar incidence case. 
Finally, when a non-uniform thermal load was applied, the CP shifted away from the origin by $0.04 \mathrm{~mm}(0.98 \%)$ along the y-axis which is the same distance predicted for the first solar incidence case.

Finally, performance was predicted due to the thermal effects of the $35^{\circ}$ off-normal $\left(\gamma=35^{\circ}\right), 22.5^{\circ}$ off-axis $\left(\varphi=22.5^{\circ}\right)$ solar incidence. A roll torque was detected due to the asymmetric sail shape induced by the $22.5^{\circ}$ off-axis case. This roll torque is small, however, less than $0.5 \%$ of a typical pitch or yaw torque coefficient listed in Table 2.

The pitch and yaw torques differed throughout each load sub-set for this sun-line case. This is expected for a sun-line that does not lay equidistant from the pitch and yaw axes. The individual magnitudes of these torque coefficients were not greater than those reported for previous cases. Sail thrust changed by a similar measure to the previous two cases as well, verifiable in Table 2.

Moderate changes in the sail CP were again detected. Even before a thermal load was applied, the z-component and the y-component of the $\mathrm{CP}$ were not the same. Then as a uniform temperature was applied both the z-component and $\mathrm{y}$-component shifted back to the origin by $0.1 \mathrm{~mm}$. And when a non-uniform thermal load was applied, the CP shifted away from the origin by $0.03 \mathrm{~mm}(1.15 \%)$ along the $\mathrm{z}$-axis and by $0.03 \mathrm{~mm}(1.13 \%)$ along the y-axis, slightly less effect than detected for the $45^{\circ}$ off-axis sun-line case.

\section{Conclusion}

Significance of thermally induced strains on sail shape and sail performance was successfully investigated for several $35^{\circ}$ off-normal solar incidence cases. A shape model analysis procedure was developed to predict solar sail topology variation due to these thermal effects. This model iterates many times between an MSC NASTRAN predicted sail shape and a MATLAB predicted sail temperature distribution before converging on a final sail topology. Sail topologies were passed through IODA-Sail software to calculate final changes in sail performance.

Overall, thermal effects were found to be deterministic due to the three $35^{\circ}$ off-normal solar incidence cases. The greatest temperature gradient predicted across a single sail quadrant was $0.44^{\circ} \mathrm{C}$ for the $35^{\circ}$ off-normal, $22.5^{\circ}$ off-axis case. A smaller $0.2{ }^{\circ} \mathrm{C}$ gradient was predicted for the $35^{\circ}$ off-normal, $45^{\circ}$ off-axis case. This temperature change caused a $2.7 \%$ increase in maximum sail deflection from $3.82 \mathrm{~mm}$ to $3.92 \mathrm{~mm}$. It turns out that this change in sail deflection was of the same order of magnitude as the change in sail deflection due to a uniform $14.5{ }^{\circ} \mathrm{C}$ decrease caused by the transition from normal to off-normal solar incidence on a flat-sail.

Sail performance changes were found to be moderate for the three solar incidence cases. No roll torque was detected on the full-system model for the on-axis case and the $45^{\circ}$ off-axis case as suspected for a sun-line orientation that produces a symmetric topology. A system-wide roll torque will not arise if the full-system sail shape is symmetric about the sun line. The $22.5^{\circ}$ off-axis sun-line did induce minor asymmetries in sail shape which caused a small roll torque to appear.

Pitch and yaw torques changed by as much as $4 \%$ due to the off-normal incidence thermal effects. Normal thrust did not change appreciably, and tangential thrust changed by only $0.4 \%$ in the most extreme case. The CP, however, shifted by a maximum of over $3 \%(0.14 \mathrm{~mm})$ along the pitch axis. In fact, this shift in CP may be large enough to induce sail instability if not accounted for in the sail attitude control system.

It may be interesting to note that sail topology was affected by non-uniform heating in a somewhat counterintuitive fashion. One would intuitively expect the hotter sail regions to sag more and the colder regions to sag less. This was not the case. In fact, the hotter sail regions sagged less and colder regions sagged more.

Overall, thermal effects were found to be deterministic although not as severe as initially suspected. It should be noted that realistically sized sails will be 40 to 100 meters length on one side, and this study focused on sails of 20 meter length. For larger sail sizes, one would expect the maximum sail deflection to increase as well as the sail temperature gradients. Naturally, performance effects may also be magnified for sail sizes much larger than the 20meter $\mathrm{S}^{4}$ system investigated here.

Analysis techniques developed through this thesis research are intended to aid future solar sail and other gossamer spacecraft development efforts. This shape model may prove to be a valuable resource for high-fidelity predictions of thermal effects on gossamer spacecraft.

\section{Acknowledgments}

Support of this research was provided by NASA's In-Space Propulsion office, by an award from the NASA Langley Research Center Structural Dynamics Branch sponsored by Mr. Richard Pappa, and by an award from the South Dakota Space Grant Consortium coordinated by Mr. Tom Durkin and Dr. Ed Duke. The authors would like to thank Mr. Tom Jones from NASA LaRC Advanced Sensing and Optical Measurement Branch for his contributions to testing of the 20 meter solar sail system. The authors would also like to recognize Alliant Techsystems Space Systems Company for supplying data on the $\mathrm{S}^{4}$ system. 


\section{References}

${ }^{1}$ Murphy, D., Wie, B., "Robust Thrust Control Authority for Scalable Sailcraft," $14^{\text {th }}$ AAS/AIAA Space Flight Mechanics
Conference, 04-285, AIAA, Maui, Hawaii, 2004 .
${ }^{2}$ Chmielewski, A., "Overview of Gossamer Structures," Gossamer Spacecraft: Membrane and Inflatable Structures Technology for Space Applications, Edited by C.H.M. Jenkins, Vol. 191, Progress in Astronautics and Aeronautics, AIAA, Virginia, 2001, pp. 1-33.

${ }^{3}$ Salama, M., McInnes, C., Mulligan, P., “Gossamer Sailcraft Technology,” Gossamer Spacecraft: Membrane and Inflatable Structures Technology for Space Applications, edited by C. H. M. Jenkins, Vol. 191, Progress in Astronautics and Aeronautics, AIAA, Virginia, 2001, pp. 481-501.

${ }^{4}$ Garbe, G., Wie, B., Murphy, D., Ewing, A., Lichodziejewski, L., Derbes, B., Campbell, B., Wang, J., Taleghani, B., Canfield, S., Beard III, J., Peddieson, J., "Solar Sail Propulsion Technology Development," Recent Advances in Gossamer Spacecraft, edited by C. H. M. Jenkins, Vol. 212, Progress in Astronautics and Aeronautics, AIAA, Virginia. unpublished

${ }^{5}$ Leifer, J., "A Simplified Computational Model for Shear Compliant Borders in Solar Sails," $46^{\text {th }}$ AIAA Structures, Structural Dynamics and Materials Conference, 2005-2056, AIAA, Austin, Texas, 2005.

6 Jenkins, C.H., Hossain, A., Woo, K., Igawa, H., Wang, J., Sleight, D., and Tessler, A., "Membrane Wrinkling," Chapter 3 in Recent Advances in Gossamer Spacecraft, edited by C.H.M. Jenkins, Vol. 212, Progress in Astronautics and Aeronautics, AIAA, Virginia, 2006. unpublished

7 "Solar Sail Test Report," SRS Technologies Support to NASA Glenn Research Center, NNC04QA27P, Huntsville, Alabama, Aug., 2004.

${ }^{8}$ McInnes C. R., Solar Sailing: Technology, Dynamics, and Mission Applications, $1^{\text {st }}$ ed., Springer-Praxis, London, UK, 1999, pp. 47-49.

${ }^{9}$ Miles, J. J., Blandino, J. R., Jenkins, C. H. M., Pappa, R. S., Banik, J. A., Brown, H., McEvoy, K., "Evaluation of Microbolometer-Based Thermography for Gossamer Space Structures," SPIE Optics and Photonics Symposia, San Diego, California, 2005.

10 Perrygo, C., "Solar Shades," Gossamer Spacecraft: Membrane and Inflatable Structures Technology for Space Applications, edited by C. H. M. Jenkins, Vol. 191, Progress in Astronautics and Aeronautics, AIAA, Virginia, 2001, pp. 503526.

${ }^{11}$ Banik, J., "Thermal/Structural Effects on Solar Sails," Masters Thesis, Mechanical Engineering Dept., South Dakota School of Mines and Technology, Rapid City, SD, 2005.

${ }^{12}$ MSC/NASTRAN Handbook for Nonlinear Analysis, edited by S. H. Lee, The MacNeal Schwendler Corporation, 1992.

${ }^{13}$ MSC.NASTRAN Quick Reference Guide, MSC.Software Corporation, 2001.

${ }^{14}$ Cengel, Y. A., Heat Transfer A Practical Approach, 2nd ed., McGraw Hill, New York, 2003, pp. 561-599.

15 Taleghani, B., Lively, P., Banik, J., "Test/Analysis Correlation of a 20 Meter Solar Sail System" 53 ${ }^{\text {rd } J A N N A F ~ P r o p u l s i o n ~}$ Meeting, JANNAF, Monterey, California, 2005.

16 Jenkins, C., Schur, W., Greschik, G., "Mechanics of Membrane Structures," Gossamer Spacecraft: Membrane and Inflatable Structures Technology for Space Applications, edited by C. H. M. Jenkins, Vol. 191, Progress in Astronautics and Aeronautics, AIAA, Virginia, 2001, pp. 49-110.

${ }^{17}$ Moore, J. D., Gierow, P. A., Troy, E., "High Fidelidy Finite Element Based Modeling for Solar Sail Thrust Vector Prediction from Flexible Sail Models," SRS Technologies support of NASA Marshall Space Flight Center, NNM04AD60P, Huntsville, Alabama.

${ }^{18}$ Murphy, D., McEachen, M., Macy, B., Gaspar, J., "Demonstration of a 20-m Solar Sail System," 46 ${ }^{\text {th }}$ AIAA Structures, Structural Dynamics and Materials Conference, 2005-2126, AIAA, Austin, Texas, 2005.

${ }^{19}$ Taleghani, B., Lively, P., Gaspar, J., Murphy, D., Trautt, T., "Dynamic And Static Shape Test/Analysis Correlation of a 10-Meter Quadrant Sail," $46^{\text {th }}$ AIAA Structures, Structural Dynamics and Materials Conference, 2005-2123, AIAA, Austin, Texas, 2005.

${ }^{20}$ Murphy, D., Trautt, T., McEachen, M., Eskenazi, M., Messner, D., "Progress and Plans for System Demonstration of a Scalable Square Solar Sail," $14^{\text {th }}$ AAS/AIAA Space Flight Mechanics Conference, 04-105, AIAA, Maui, Hawaii, 2004.

${ }^{21}$ Derbes, B., Lichodziejewski, D., Ellis, J., Scheeres, D., "Sailcraft Coordinate Systems and Format for Reporting Propulsive Performance," $14^{\text {th }}$ AAS/AIAA Space Flight Mechanics Conference, 04-100, AIAA, Maui, Hawaii, 2004. 